\title{
Exploring the Relationship of Perivascular Adipose Tissue Inflammation and the Development of Vascular Pathologies
}

\author{
Afifah Zahirah Abd Rami $\mathbb{D}^{1}$, Adila A. Hamid $\mathbb{D}^{1},{ }^{1}$ Nur Najmi Mohamad Anuar $\mathbb{D}{ }^{2}$ \\ Amilia Aminuddin (D, ${ }^{1}$ and Azizah Ugusman iD ${ }^{1}$ \\ ${ }^{1}$ Department of Physiology, Faculty of Medicine, Universiti Kebangsaan Malaysia, Jalan Yaacob Latif, Cheras, \\ 56000 Kuala Lumpur, Malaysia \\ ${ }^{2}$ Center for Toxicology \& Health Risk Studies, Faculty of Health Sciences, Universiti Kebangsaan Malaysia, Jalan Raja Muda \\ Abd Aziz, 50300 Kuala Lumpur, Malaysia
}

Correspondence should be addressed to Amilia Aminuddin; amilia@ppukm.ukm.edu.my and Azizah Ugusman; dr.azizah@ppukm.ukm.edu.my

Received 1 October 2021; Revised 11 January 2022; Accepted 21 January 2022; Published 8 February 2022

Academic Editor: Agnieszka Dobrzyn

Copyright (c) 2022 Afifah Zahirah Abd Rami et al. This is an open access article distributed under the Creative Commons Attribution License, which permits unrestricted use, distribution, and reproduction in any medium, provided the original work is properly cited.

\begin{abstract}
Initially thought to only provide mechanical support for the underlying blood vessels, perivascular adipose tissue (PVAT) has now emerged as a regulator of vascular function. A healthy PVAT exerts anticontractile and anti-inflammatory actions on the underlying vasculature via the release of adipocytokines such as adiponectin, nitric oxide, and omentin. However, dysfunctional PVAT produces more proinflammatory adipocytokines such as leptin, resistin, interleukin- (IL-) 6, IL-1 $\beta$, and tumor necrosis factor-alpha, thus inducing an inflammatory response that contributes to the pathogenesis of vascular diseases. In this review, current knowledge on the role of PVAT inflammation in the development of vascular pathologies such as atherosclerosis and hypertension was discussed.
\end{abstract}

\section{Introduction}

Cardiovascular diseases (CVD) have been widely known for decades as the leading cause of mortality worldwide. According to the World Health Organization (WHO), in 2019, an estimated 17.9 million deaths due to CVD were recorded, representing $32 \%$ of global deaths [1]. This alarming situation raises the importance of investigating the pathophysiological aspects of CVD. Perivascular adipose tissue (PVAT) surrounds most blood vessels and has been implicated in the pathophysiology of CVD due to its proximity and crosstalk with the underlying vasculature, with PVAT inflammation suggested to be contributing to the development of vascular diseases. A link between PVAT, inflammation, and CVD was first discovered two decades ago when a study showed an increase in leukocyte infiltration in the PVAT in response to coronary angioplasty [2]. This signifies the role of PVAT inflammation in the pathophysiology of CVD and as a potential future therapeutic target.

\section{Perivascular Adipose Tissue}

PVAT consists of adipocytes that surround most systemic blood vessels, except the cerebral vasculature [3]. Structurally, PVAT consists of adipocytes, fibroblasts, stem cells, lymphocytes, and macrophages. The characteristics of PVAT differ in different anatomical sites. For example, thoracic aorta PVAT (tPVAT) and abdominal aorta PVAT (aPVAT) are two subtypes of PVAT which possess different phenotypes and functions. In rodents, tPVAT's characteristics are more similar to brown adipose tissue (BAT), while aPVAT is phenotypically a mixture of white adipose tissue (WAT) and BAT, whereas in humans, coronary PVAT's characteristics are more similar to WAT [4-6]. tPVAT is mainly 
involved in lipolysis and heat generation and facilitates vascular relaxation via adipokine release, whereas aPVAT is involved in lipid storage and cytokine secretion and contains more macrophages and immune cells [7]. Hence, aPVAT is regarded to be more prone to proinflammatory activity and is proatherogenic compared to tPVAT.

Studies have shown that each type of adipocyte is derived from a specific precursor and is differentiated at separate times during embryogenesis [8, 9]. Most white adipocytes are differentiated from $\mathrm{Myf5}^{+}$and $\mathrm{PAX}^{+}$precursors or Myf5 ${ }^{-} / \mathrm{Pax}^{+}$, while brown adipocytes are derived from paraxial mesoderm $\mathrm{Myf}^{+} / \mathrm{Pax}^{+} / \mathrm{Pax}^{+} / \mathrm{En} 1^{+}$, a common precursor of myocytes [10]. Peroxisome proliferatoractivated receptor- (PPAR-) $\gamma$ is a transcription factor that is involved in the regulation of gene expression and differentiation of adipocytes [11]. Deletion of PPAR- $\gamma$ during BAT adipogenesis impairs PVAT development and increases local inflammation, which often leads to the progression of atheromatous plaque and myocardial injury in vivo $[12,13]$. The activation of PPAR- $\gamma$ has been shown to attenuate arterial stiffening and reduce inflammatory and oxidative stress in the PVAT of obese mice [14]. These findings highlight the significant role of PPAR- $\gamma$ in PVAT in modulating inflammation and risk of vascular diseases.

Although PVAT was initially regarded as a structural support organ for the vasculature, recent findings have demonstrated its physiological importance, especially in regulating vascular tone and function [15]. In healthy subjects, PVAT functions as an endocrine and paracrine organ that secrets more anti-inflammatory, antiatherogenic, and vasorelaxant adipokines such as adiponectin, omentin, vaspin, angiotensin 1-7, methyl palmitate, and nitric oxide (NO), which contribute to its anticontractile, anti-inflammatory, and antiatherogenic actions $[16,17]$. However, in the presence of vascular diseases such as hypertension, atherosclerosis, and obesity, PVAT becomes dysfunctional. A dysfunctional PVAT secretes less anti-inflammatory adipocytokines and more proinflammatory adipocytokines such as leptin, interleukin- (IL-) 6, tumor necrosis factor-alpha (TNF- $\alpha$ ), and monocyte chemoattractant protein-1 (MCP1) $[18,19]$. These trigger inflammatory responses that lead to vascular dysfunction and an increased risk of developing CVD (Figure 1).

\section{PVAT-Derived Anti- Inflammatory Adipocytokines}

Adiponectin is one of the most abundant adipokines secreted by PVAT with anticontractile and anti-inflammatory effects on the vascular wall. Adiponectin acts via two types of receptors: adiponectin receptor 1 (AdipoR1) and adiponectin receptor 2 (AdipoR2) [20]. Adiponectin exerts its antiinflammatory effects by decreasing the expression of proinflammatory cytokines such as IL- 6 and TNF- $\alpha$ and suppressing the production of cellular adhesion molecules by inhibiting the nuclear factor kappa-B (NF- $\kappa \mathrm{B})$ pathway [21]. Moreover, hypoadiponectinemia results in endothelial dysfunction, and this is mediated by Nod-like receptor family pyrin domain-containing 3 (NLRP3) inflammasome activation [22]. Adiponectin knock-out mice showed an increase in the gene expression of inflammatory markers such as TNF- $\alpha$ and MCP-1. This further proves the antiinflammatory action of adiponectin [23].

Omentin secreted by PVAT also has an antiinflammatory effect. In obese mice, omentin reduces the expression of proinflammatory cytokines such as IL-6, IL$1 \beta$, and TNF- $\alpha$ and increases the secretion of other antiinflammatory adipocytokines such as adiponectin and IL10 through the inhibition of thioredoxin-interacting protein (TXNIP)/NLTP3 signaling pathway [24]. Furthermore, omentin reduces oxidative stress, mitochondrial dysfunction, proinflammatory cytokines (IL-6, IL-8, and MCP-1), cyclooxygenase-2 (COX), and prostaglandin E2 (PGE2) in lipopolysaccharide-induced macrophages [25]. Omentin protects against vascular endothelial dysfunction by suppressing endoplasmic reticulum (ER) and oxidative stress. This is achieved through the activation of AMP-activated protein kinase (AMPK)/PPAR- $\delta$ pathway that stimulates NO release [26]. In free fatty acid-induced endothelial cells, omentin decreases proinflammatory agents (MCP-1, IL-6, IL-1, ICAM-1, TNF- $\alpha$ ) and NF- $\kappa$ B activation [27].

Fibroblast growth factor-21 (FGF-21) is a growth factor expressed in multiple tissues and organs such as adipose tissue, liver, and pancreas that regulates insulin signaling, glucose, and lipid metabolism [28]. FGF-21 exerts antiinflammatory effects in macrophages and obese adipose tissue via various inflammatory signaling pathways [29, 30]. Treatment of apolipoprotein E-deficient $\left(\mathrm{ApoE}^{-/-}\right)$mice with FGF-21 reduced atherosclerosis formation by increasing adiponectin expression and inhibiting ER stress, NLRP3 inflammasome activation, and factor-associated suicide (FAS) signaling [31-33]. FGF-21 also improves oxidativestress-induced endothelial dysfunction by activating the calcium/calmodulin-dependent protein kinase kinase 2 (CaMKK2)/AMPK $\alpha$ pathway [34].

Vaspin, which is also known as visceral adipose tissuederived serine protease inhibitor, is an anti-inflammatory adipokine that improves insulin sensitivity [35]. A study has reported that vaspin inhibits the gene expression of leptin receptor, production of TNF- $\alpha$, and NF- $\kappa \mathrm{B}$ activation in leptin-induced rat chondrocytes [36] This suggests an important role of vaspin produced by PVAT in modulating inflammatory reactions. Meanwhile, interleukin-10, which is produced by $\mathrm{T}$ cells, $\mathrm{B}$ cells, and macrophages in the PVAT, plays a significant role in preventing inflammation [37]. IL-10 suppresses proinflammatory cytokine secretion and prevents macrophage and dendritic cell maturation [38]. IL-10 acts on heterodimeric IL-10 receptors (IL-10R1, IL-10R2), which activates the Janus kinase (JAK)/STAT signaling pathway. This leads to inhibition of proinflammatory mediator production [39].

Another PVAT-derived anti-inflammatory factor is NO. Vascular NO is produced mainly by endothelial NO synthase (eNOS) [40]. NO inhibits vascular smooth muscle proliferation and migration, platelet aggregation, leukocyte adhesion, and inflammation [41]. eNOS, which is mainly expressed in the endothelium, has also been found to be present in PVAT [42]. PVAT-derived adiponectin increases 

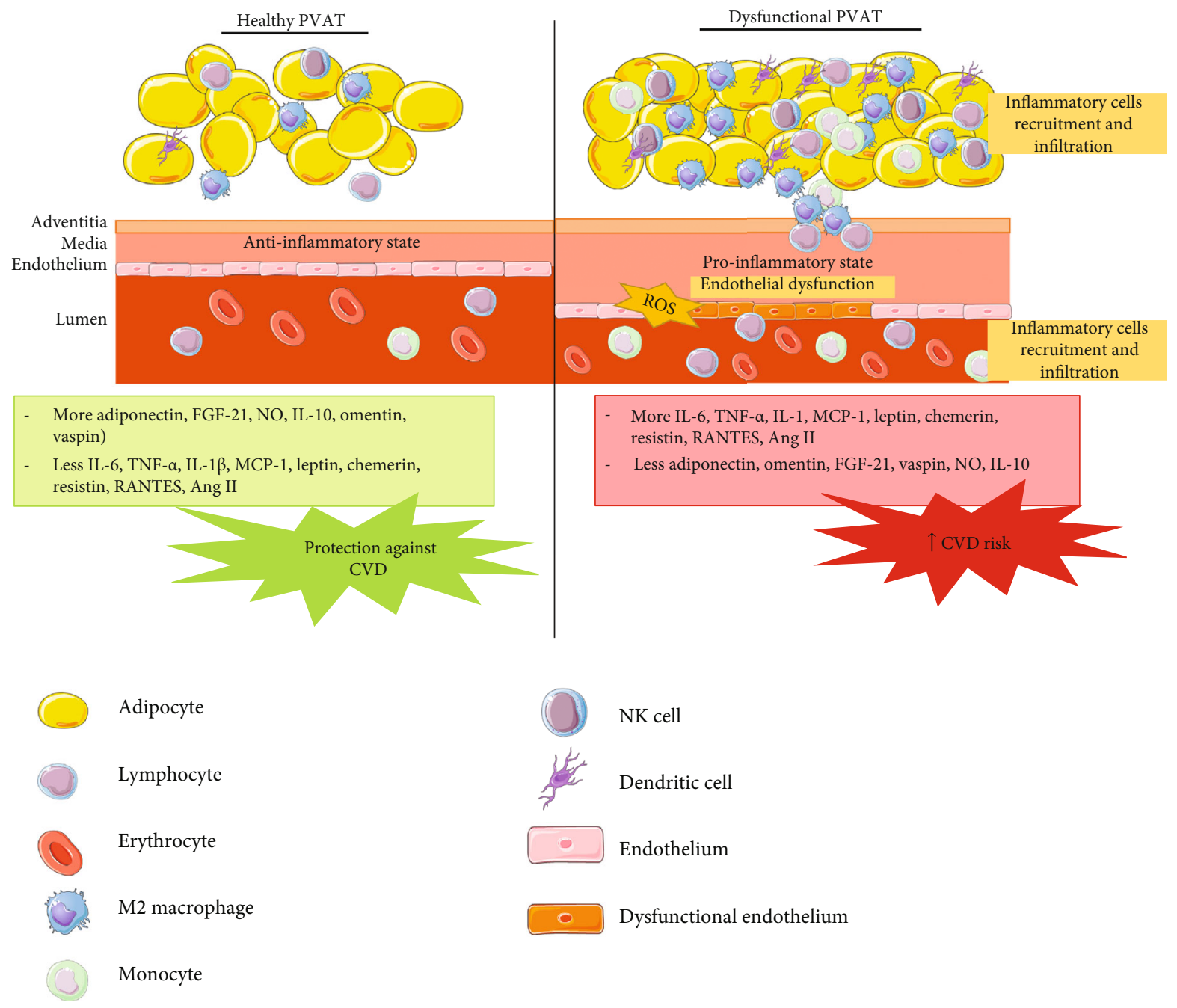

Figure 1: The anti-inflammatory state of healthy perivascular adipose tissue (PVAT) compared to the proinflammatory state of dysfunctional PVAT. CVD: cardiovascular diseases; FGF-21: fibroblast growth factor-21; IL: interleukin; MCP-1: monocyte chemoattractant protein-1; NO: nitric oxide; RANTES: regulated on activation, normal $\mathrm{T}$ cell expressed, and secreted; ROS: reactive oxygen species; TNF- $\alpha$ : tumor necrosis factor-alpha.

eNOS phosphorylation, thus enhancing NO production. Endothelial dysfunction is characterized by the reduction of NO bioavailability, and this is associated with inflammation and development of atherosclerosis and hypertension [42].

\section{PVAT-Derived Proinflammatory Adpocytokines}

IL- 6 is one of the most studied proinflammatory cytokines secreted by PVAT. IL-6 can directly act on endothelial cells to increase superoxide production, thus leading to endothelial dysfunction [18]. Another prominent cytokine that modulates PVAT inflammatory response is TNF- $\alpha$. TNF- $\alpha$ is released by a few types of cells including monocytes, vascular cells, and adipocytes. It inhibits the eNOS expression and stimulates the production of reactive oxygen species (ROS) via activation of the NF- $\kappa \mathrm{B}$ pathway [18]. Other proinflammatory cytokines released by PVAT include MCP-1 and IL-
$1 \beta$. MCP-1 plays a crucial role in facilitating the infiltration of macrophages into the vascular wall and is often associated with the pathogenesis of atherosclerosis [43]. Meanwhile, IL$1 \beta$ induces the MCP-1 expression via NF- $\kappa \mathrm{B}$ and activator protein-1 (AP-1) activation [44].

Chemerin, also known as tazarotene-induced gene 2 (TIG2), is a chemoattractant protein that regulates the immune response, metabolism, and inflammation. Although some studies have associated chemerin with antiinflammatory actions, its function is mainly considered as proinflammatory [45]. Chemerin is expressed in adipose tissue including PVAT and visceral adipose tissue [46, 47]. Both chemerin and its receptor, CMKLR1, are upregulated in obesity [48]. Furthermore, chemerin recruits dendritic cells into adipose tissue, thus increasing the inflammatory reaction in adipocytes [49]. Chemerin also stimulates the recruitment and retention of macrophages at inflammation sites by inducing macrophage adhesion to extracellular matrix proteins and adhesion molecules [50]. The level of 
chemerin is closely correlated with the level of other proinflammatory cytokines such as TNF- $\alpha$, C-reactive protein (CRP), and IL-6, which further supports chemerin's proinflammatory action [51].

Leptin has been suggested as a PVAT-derived proinflammatory factor as its expression can be stimulated by other proinflammatory mediators such as IL- 1 and TNF- $\alpha$, and its concentration increases during pathological conditions such as fever and sepsis [52]. Leptin activates monocytes, leukocytes, and macrophages to secrete TNF- $\alpha$, IL-6, and IL-12, increases CC-chemokine ligand production in macrophages, and stimulates ROS generation [38]. Additionally, leptin causes endothelial dysfunction [53] by inducing CRP production, cellular adhesion molecules, and platelet tissue factors in endothelial cells [54].

Resistin is another proinflammatory adipokine released by PVAT that enhances the expression of IL- 6, IL- $1 \beta$, and TNF- $\alpha$ via NF- $\kappa$ B signaling [55]. Other than adipocytes, resistin is released by immune cells including monocytes and macrophages, and this suggests its role in atherogenesis. Moreover, resistin causes endothelial dysfunction by enhancing proinflammatory markers such as MCP-1, TNF- $\alpha$, IL-6, long pentraxin 3 , IL- $1 \beta$, vascular cell adhesion molecule-1 (VCAM-1), and intercellular adhesion molecule-1 (ICAM-1). Besides, resistin promotes oxidative stress and ER stress, thus leading to mitochondrial dysfunction and redox imbalance $[56,57]$.

The components of the renin angiotensin aldosterone system are expressed in PVAT. Its bioactive peptide, angiotensin II (Ang II), exerts its inflammatory effect by stimulating the expression of adhesion molecules and cytokines such as MCP-1 and IL-6 [58]. Ang II is also reported to induce immune cells including $\mathrm{T}$ lymphocytes, $\mathrm{M} 1$ and M2 macrophages, and dendritic cell infiltration in PVAT $[59,60]$. Interestingly, a large proportion of these cells, particularly $\mathrm{T}$ lymphocytes, bear regulated on activation, normal $\mathrm{T}$ cell expressed, and secreted (RANTES) CC chemokine receptor (CCR)1, CCR3, and CCR5 receptors. Expression of RANTES chemokine receptors is stimulated by Ang II [61]. RANTES, also known as CC chemokine ligand 5 (CCL5), is present in both human and mouse adipose tissue. RANTES acts as a chemoattractant for inflammatory cells, particularly $\mathrm{T}$ cells, and it is associated with the development of atherosclerosis and hypertension [62]. The summary of anti- and proinflammatory adipocytokines secreted by PVAT and its involvement in vascular diseases is summarized in Table 1.

\section{PVAT Inflammation in Vascular Diseases}

5.1. Atherosclerosis. Atherosclerosis is an inflammatory disease involving the formation of fibrofatty plaques in the arterial wall that can progress to several chronic diseases such as coronary artery disease (CAD), stroke, and peripheral artery disease [63]. The atherosclerotic plaque consists of the accumulation of fatty substances, cholesterol, calcium, cellular waste products, and fibrin [64]. Several risk factors are closely related to atherosclerosis, including hypertension, tobacco smoking, obesity, and diabetes [65]. Traditionally, the pathogenesis of atherosclerosis has been described as an "inside-to-outside" model that starts with endothelial dysfunction, inflammation, and formation of foam cells [66]. However, in most vascular studies, PVAT was removed from the underlying blood vessels prior to experiments as PVAT was considered to be a nonvascular and inactive tissue [67].

Interestingly, more current studies propose that the crosstalk between PVAT and the underlying vasculature happens in two directions, with an "outside-to-inside" inflammatory signaling activated by the dysfunctional PVAT [68-70]. For example, it was demonstrated that inflammation in the PVAT and adventitial layer happened prior to the development of endothelial dysfunction and formation of atherosclerotic plaques in apolipoprotein Edeficient $\left(\mathrm{ApoE}^{-/-}\right)$mice [71]. Perivascular adipocytes send signals to both immune cells and endothelial cells via the release of adipocytokines to modulate the inflammatory crosstalk in atherogenesis [72]. PVAT plays a crucial role in the pathogenesis of atherosclerosis through mechanisms involving endothelial dysfunction and inflammatory cell recruitment and infiltration [70,73].

Immune cell infiltration is an important step in PVAT inflammation and atherosclerosis. $\mathrm{T}$ cell infiltration in PVAT may occur prior to macrophage infiltration in mice [74]. Both proatherogenic $\left(\mathrm{CD}^{+} \mathrm{T}\right.$ helper (Th), $\mathrm{CD}^{+} \mathrm{T}$ cytotoxic (Tc)), and atheroprotective (T regulatory (Treg)) T cells are found in PVAT [75-77]. Th1, Tc1, and Th17 cells release proinflammatory cytokines such as interferon- $\gamma$ (IFN- $\gamma$ ), IL-7, and TNF- $\alpha$, whereas Treg cells secrete antiinflammatory cytokine, IL-10 [78, 79]. Subpopulation of T cells such as natural killer $\mathrm{T}$ cells also release IFN- $\gamma$ and TNF- $\alpha$ in PVAT [80].

\subsection{Mechanisms Linking PVAT Inflammation to} Atherosclerosis. The endothelium acts as a physical barrier between blood and the vascular wall. Besides, the endothelium also secretes bioactive molecules involved in the regulation of vascular tone, vascular remodeling, inflammatory process, and thrombosis [81]. NO produced by eNOS is an important antiatherogenic molecule, and reduced NO bioavailability is the hallmark of endothelial dysfunction [82]. Endothelial dysfunction is well established as the precursor of atherosclerosis. A dysfunctional endothelium loses its physiological characteristics and transforms into a proinflammatory, prothrombotic, and vasoconstrictor state, thus promoting atherosclerosis [83].

As described earlier, in physiological condition, PVAT produces a range of vasoprotective adipocytokines with antiatherogenic effects such as adiponectin, NO, and hydrogen sulfide $\left(\mathrm{H}_{2} \mathrm{~S}\right)$ [84]. Reduced $\mathrm{NO}$ and $\mathrm{H}_{2} \mathrm{~S}$ have been shown to worsen atherosclerosis progression [82, 85]. Unsurprisingly, since atherosclerosis is closely related to obesity, PVAT-derived $\mathrm{NO}, \mathrm{H}_{2} \mathrm{~S}$, and adiponectin levels were reduced in obese animals [86-89]. It is postulated that in obesity, increased PVAT mass and hyperthrophic adipocytes in PVAT promote endothelial dysfunction and atherosclerosis through increased oxidative stress and inflammation [90, 91].

Breakdown of fat in hypertrophic PVAT releases free fatty acids (FFA) into the vasculature. FFA causes 
TABLe 1: Anti- and proinflammatory adipocytokines secreted by PVAT and its involvement in vascular diseases.

\begin{tabular}{|c|c|c|}
\hline Adipokine/cytokine & Effect on vasculature & Association with vascular diseases \\
\hline \multicolumn{3}{|c|}{ Anti-inflammatory adipocytokines } \\
\hline Adiponectin & $\begin{array}{l}\text { (i) Vasodilator [169] } \\
\text { (ii) } \downarrow \text { adhesion molecule expression [170] } \\
\text { (iii) } \downarrow \text { oxidative stress [171] }\end{array}$ & (i) $\downarrow$ production in obesity [172] and hypertension [173] \\
\hline Omentin & $\begin{array}{l}\text { (i) } \downarrow \text { oxidative stress [25] } \\
\text { (ii) } \downarrow \text { mitochondrial dysfunction [25] } \\
\text { (iii) } \uparrow \text { NO [174] }\end{array}$ & (i) $\downarrow$ expression in obesity [175] and CAD [176] \\
\hline FGF-21 & $\begin{array}{l}\text { (i) } \downarrow \text { oxidative stress [177] } \\
\text { (ii) } \uparrow \text { vasorelaxation }[178]\end{array}$ & (i) Improves vascular dysfunction in hypertension [179] \\
\hline Vaspin & $\begin{array}{l}\text { (i) } \uparrow \text { insulin sensitivity [35] } \\
\text { (ii) } \uparrow \text { cytokine production [35] }\end{array}$ & (i) $\downarrow$ production in atherosclerosis $[180]$ \\
\hline Nitric oxide & (i) Vasorelaxant [167] & (i) $\downarrow$ production in atherosclerosis [181] and hypertension [182] \\
\hline IL-10 & (i) $\downarrow$ immune cell infiltration [37] & (i) $\downarrow$ in atherosclerosis [183] \\
\hline \multicolumn{3}{|c|}{ Proinflammatory adipocytokines } \\
\hline IL-6, TNF- $\alpha$, IL-1, MCP-1 & $\begin{array}{l}\text { (i) } \uparrow \text { immune cell infiltration [184] } \\
\text { (ii) Endothelial dysfunction [90] } \\
\text { (iii) } \uparrow \text { ROS [185] }\end{array}$ & (i) $\uparrow$ production in obesity $[184]$ and atherosclerosis $[186,187]$ \\
\hline Chemerin & $\begin{array}{l}\text { (i) } \uparrow \text { immune cell infiltration [188] } \\
\text { (ii) } \uparrow \text { adhesion molecule expression [189] }\end{array}$ & (i) $\uparrow$ production in obesity and diabetes $[190]$ \\
\hline Leptin & $\begin{array}{l}\text { (i) } \uparrow \text { immune cell infiltration [54] } \\
\text { (ii) } \uparrow \text { ROS [191] } \\
\text { (iii) endothelial dysfunction [192] }\end{array}$ & (i) $\uparrow$ production in obesity, hypertension [192], and CAD [193] \\
\hline Resistin & $\begin{array}{l}\text { (i) } \uparrow \operatorname{ROS~[56]} \\
\text { (ii) } \uparrow \text { macrophage infiltration [56] }\end{array}$ & (i) $\uparrow$ production in atherosclerosis [194] \\
\hline RANTES, Ang II & (i) $\uparrow$ immune cell infiltration [62] & (i) $\downarrow$ production in atherosclerosis [195] and hypertension [196] \\
\hline
\end{tabular}

Abbreviations: Ang II: angiotensin II; CAD: coronary artery disease; IL: interleukin; MCP: monocyte chemoattractant protein; NO: nitric oxide; ROS: reactive oxygen species; TNF- $\alpha$ : tumor necrosis factor-alpha.

phosphorylation of insulin receptor substrate 1 (IRS-1) present in PVAT and other vascular cells by activating NF- $\kappa \mathrm{B}$, protein kinase $C(\mathrm{PKC})$, and Toll-like receptors [92]. This decreases the activation of downstream PI3K/Akt signaling, leading to inhibition of eNOS expression and NO synthesis [93]. Besides, PKC activation by FFA causes eNOS coupling, resulting in further reduction in $\mathrm{NO}$ synthesis and production of reactive oxygen species (ROS) [7, 94]. Furthermore, PKC induces the synthesis of endothelin-1 (ET-1), which is a potent vasoconstrictor. Reduced NO bioavailability, increased vasoconstrictor, and ROS accumulation result in endothelial dysfunction and enhance the development of atherosclerosis [92].

Subsequently, monocyte recruitment and activation ensue. Dysfunctional PVAT releases more pro-inflammatory adipocytokines such as TNF- $\alpha$, leptin, and IL- 6 that induce the expression of cellular adhesion molecules like VCAM-1 and ICAM-1 on the endothelial cells. Cellular adhesion molecules promote the adherence and migration of monocytes into the subendothelial layer [95-97]. The migrated monocytes transformed into macrophages that secrete proinflammatory cytokines such as MCP-1, TNF- $\alpha$, IFN- $\gamma$, and IL-6, which further aggravate monocyte recruitment and low-density lipoprotein (LDL) oxidation [98].

The macrophages engulf oxidized LDL (oxLDL) through scavenger receptors including leptin-like oxLDL receptor-1 and CD36, leading to formation of foam cells. Foam cells are the hallmark of initial stage of atherosclerosis [98]. Furthermore, PVAT-derived adipocytokines such as leptin, TNF- $\alpha$, visfatin, and IL-6 stimulate vascular smooth muscle cell (VSMC) proliferation and migration, which is an important step in neointima formation [99, 100]. Recent evidence demonstrates that in animal models, infiltration of macrophages in the PVAT and adventitial layer is more marked compared to the intimal layer $[101,102]$. This further supports the notion that PVAT inflammation plays a significant role in atherosclerosis development.

Proinflammatory chemokines such as macrophage inflammatory protein 1- $\alpha$ (MIP- $1 \alpha$ or CCL3), MCP-1, and RANTES attract immune cells to the site of perivascular inflammation in atherosclerotic ApoE ${ }^{-/-}$mice [103-105]. PVAT of $\mathrm{ApoE}^{-/-}$mice was also found to have increased levels of IL- 6 and IL- 1 as well as macrophages and T cell infiltration [106]. However, there was a decrease in the number of B-1 cells that secrete antiatherosclerotic IgM in $\mathrm{ApoE}^{-/-}$mouse PVAT. This further worsens the atherosclerotic lesion formation in the mouse coronary artery and aorta [107]. Additionally, microRNA-19b in endothelial cell-derived microparticles promotes atherosclerosis progression in $\mathrm{ApoE}^{-/-}$mice by increasing the secretion of proinflammatory cytokines (IL-6, IL-10, and TNF- $\alpha$ ) and inducing macrophage infiltration in PVAT [108].

Interestingly, transplantation of normal PVAT from wild-type mice decreased the size of atherosclerotic plaque 
in $\mathrm{ApoE}^{-/-}$mice. This effect was mediated by the antiinflammatory action of transforming growth factor (TGF)$\beta 1$ [109]. Besides, adiponectin obtained from PVAT decreased carotid collar-induced atherosclerosis by stimulating macrophage autophagy [110]. A study demonstrated that xenotropic and polytropic retrovirus receptor 1 (Xpr1), a macrophage regulator, and TATA-box binding protein associated factor 3 (Taf3), a core transcription factor, were upregulated in the PVAT of $\mathrm{ApoE}^{-1-}$ mice. Furthermore, an upregulation of the Taf3 and Xpr1 expression was also detected in human atherosclerotic plaques [111]. This suggests that Taf3 and Xpr1 have a role in modulating the chronic inflammatory phenotype of PVAT.

Data from human studies demonstrated that PVAT derived from patients with CVD have increased expression of proinflammatory genes and decreased expression of antiinflammatory adiponectin [112-114]. For instance, the epicardial adipose tissue of patients with coronary atherosclerosis showed increased expression of IL- $1 \beta$, IL- 6 , and TNF- $\alpha$ [113] and lower expression of adiponectin [114]. The levels of inflammatory mediators such as IL- $1 \beta$, IL- 6 , and IL- 10 were elevated in the pericoronary PVAT of patients with CAD compared to patients without CAD [115]. This suggests the influence of PVAT inflammation on atherosclerosis development through an outside-to-inside manner.

Besides, the levels of protein inhibitor of activated STAT1 (PIAS1), a key negative regulator of inflammation, were reduced in PVAT obtained from patients with atherosclerotic vessel disease [116]. PIAS1 downregulates inflammation by inhibiting STAT1 and NF- $\kappa$ B signaling pathways [117, 118]. Besides, the number of macrophages in the PVAT correlates with the number of immune cells in the atherosclerotic plaque [119-121].

Unstable plaque is an important culprit for the occurrence of acute coronary syndrome. Apart from the established factors that influence plaque stability such as intraplaque neovascularization, inflammation, and intraplaque protease activity [122], PVAT inflammation has also been suggested to affect plaque stability. The number of macrophages was higher in PVAT near unstable plaques compared to the PVAT near stable plaques [123]. Furthermore, endoplasmic reticulum (ER) stress transforms adipose tissue to a proinflammatory phenotype [124]. ER stress in PVAT contributes to plaque instability by stimulating a proinflammatory factor, granulocyte macrophage colony-stimulating factor (GM-CSF), via NF- $\kappa$ B activation [125]. GM-CSF causes adipose tissue inflammation by recruiting and activating M1 macrophages [126]. The mechanisms linking PVAT inflammation and atherosclerosis are summarized in Figure 2.

\section{Hypertension}

There are several mechanisms involving PVAT that contribute to hypertension, such as loss of PVAT anticontractile effect, increase in PVAT proinflammatory adipocytokines, decrease in PVAT anti-inflammatory adipocytokines, immune cell infiltration, activation of local RAAS, and increase in vascular oxidative stress [12]. The initial site of inflammation during the development of hypertension is in the PVAT and in the border between the PVAT and the adventitial layer $[61,127,128]$.

6.1. Mechanisms Linking PVAT Inflammation to Hypertension. In hypertension, PVAT releases more proinflammatory adipocytokines such as IL-6, IL-17, IL-8, IL-23, IL- $1 \beta$, TNF- $\alpha$, and TGF- $\beta$ [129] and less anti-inflammatory adipocytokines such as adiponectin, IL-10, and IL-4 [129, 130]. Consequently, there is infiltration of immune cells in the PVAT, loss of PVAT anti-contractile action, and increased vascular resistance [19]. These events are mediated by numerous inflammatory cells and cytokines. For example, complement C5a mediates the reduction in PVAT adiponectin release [131], RANTES mediates the invasion of lymphocyte $\mathrm{T}$ cells into the perivascular space [38], and IFN- $\gamma$ is released by $\mathrm{CD}^{+}$cells that invade the PVAT [132]. All these changes intensify PVAT dysfunction and proinflammatory crosstalk between PVAT and the underlying hypertensive vessels.

A study involving spontaneously hypertensive mice induced by perilipin-1 deletion showed that the mice had higher aortic blood pressure, loss of PVAT anti-contractile effect, and decreased adiponectin expression. These findings are associated with increased expression of MCP-1, TNF- $\alpha$, and IL-6 in the aorta [133]. Meanwhile, PVAT of DOCAsalt hypertensive mice displayed an increase in the complement C3 expression, leading to increased proinflammatory M1 macrophages and decreased anti-inflammatory M2 macrophage expression in the PVAT [134]. Recruitment of proinflammatory macrophages in the PVAT of DOCA-salt hypertensive mice enhances complement activation and promotes TNF- $\alpha$ release, thereby reducing adiponectin expression [135].

During the progression of hypertension, accumulation of immune cells has been reported in the PVAT surrounding both the aorta and mesenteric arteries of hypertensive animals [18]. Hypertension is associated with a significant increase in $\mathrm{T}$ cell infiltration in the PVAT. This promotes inflammation and endothelial disyfunction via NF- $\kappa \mathrm{B}$ dependent, Notch ligand Jagged 1-regulated integrin, and adhesion molecule expression [136, 137]. Additionally, both $\mathrm{CD}^{+}$and $\mathrm{CD}^{+} \mathrm{T}$ cell subpopulations are increased in the PVAT of hypertensive mice. T cell- and monocyte-deficient mice exposed to various hypertensive stimuli showed reduced perivascular inflammatory reaction $[75,138]$.

Macrophage infiltration in PVAT is also significantly increased in hypertension, and this is regulated by $\mathrm{T}$ celldependent mechanisms [61]. Depriving the lymphocyte adaptor protein (Lnk) gene that encodes the negative regulator of T cell activation promotes PVAT inflammation, as the number of macrophages increase in both aorta and adipocytes [139]. The increase in blood pressure also corresponds with the expression of macrophage chemokine receptors CCR2 and its ligands such as CCL2, CCL7, CCL8, and CCL12 in the PVAT [140]. Moreover, the expression of proinflammatory M1 macrophage is increased in hypertension compared to healthy condition, whereby the antiinflammatory M2 macrophage is more dominant [61]. 


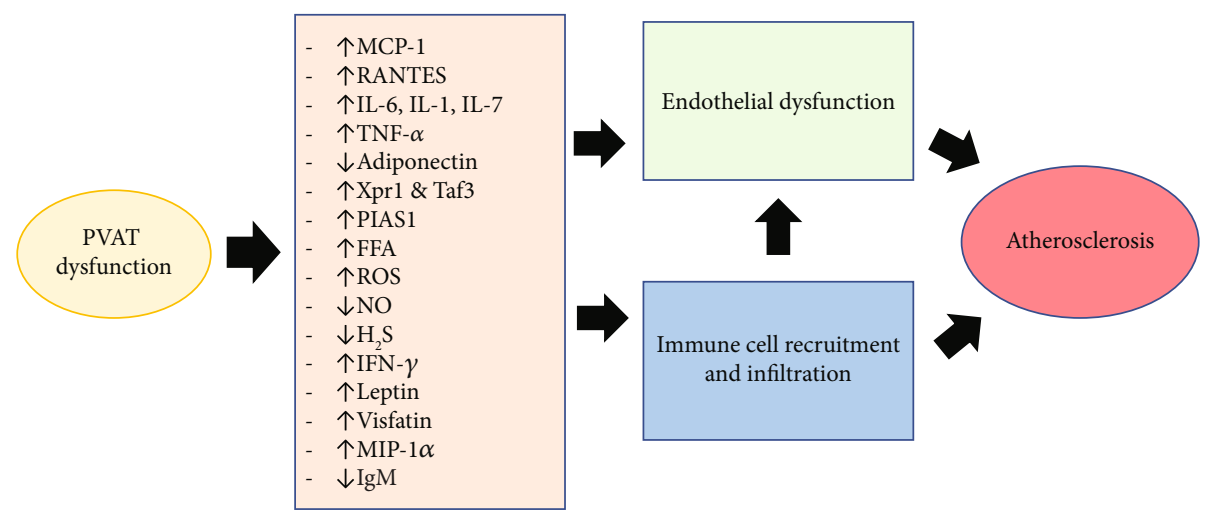

FIgURE 2: Pathways involving perivascular adipose tissue (PVAT) inflammation in atherosclerosis. FFA: free fatty acid; $\mathrm{H}_{2} \mathrm{~S}$ : hydrogen sulfide; IFN- $\gamma$ : interferon- $\gamma$; IL: interleukin; IgM: immunoglobulin $\mathrm{M}$; MCP-1: monocyte chemoattractant protein-1; MIP-1 $\alpha$ : macrophage inflammatory protein 1- $\alpha$; NO: nitric oxide; PIAS1: protein inhibitor of activated STAT1; RANTES: regulated on activation, normal T cell expressed, and secreted; ROS: reactive oxygen species; Taf3: TATA-box binding protein associated factor 3; TNF- $\alpha$ : tumor necrosis factor-alpha; Xpr1: xenotropic and polytropic retrovirus receptor 1.

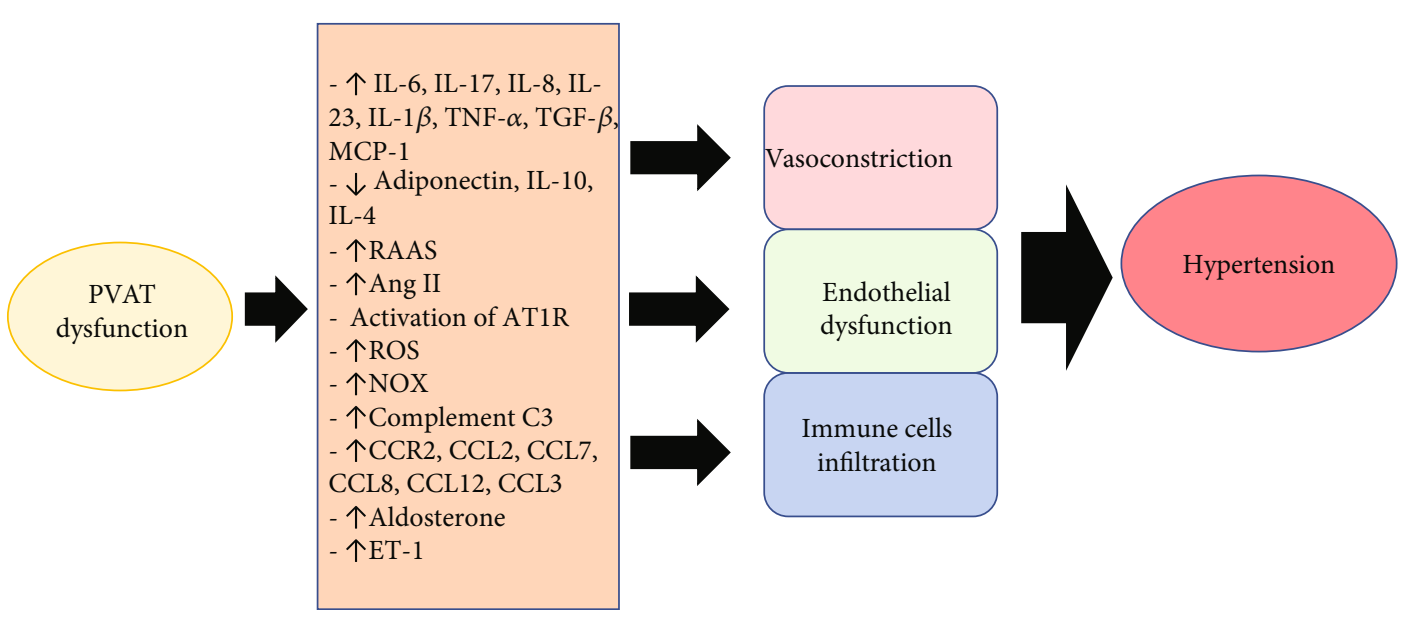

FIGURE 3: Pathways involving perivascular adipose tissue (PVAT) inflammation in hypertension. Ang II: angiotensin II; AT1R: angiotensin II type 1 receptor; C3: component 3; CCR: CC chemokine receptor; CCL: CC chemokine ligand; ET-1: endothelin-1; IL: interleukin; MCP-1: monocyte chemoattractant protein-1; NOX: NADPH oxidase; RAAS: renin-angiotensin-aldosterone system; ROS: reactive oxygen species.

Overactivation of RAAS is critical to the development of hypertension. Adipose tissue has been suggested as one of the main sites of RAAS activation in hypertensive patients [92]. In obese hypertensive patients, adipose tissues are the major source of RAAS [141]. All components of RAAS can be found in PVAT except renin [142, 143]. Angiotensinogen and Ang II levels in PVAT were significantly increased in SHR [144]. Knockout of angiotensinogen gene in PVAT successfully decreased local Ang II production in mice PVAT [145].

PVAT of Ang II-induced hypertensive mice displayed a higher number of immune cells such as macrophages, leukocytes, $\mathrm{T}$ cells, and dendritic cells. Ang II induction also enhances RANTES, MCP-1, and CCL3 expression in the periaortic PVAT and the aortic wall of the mice $[61,146]$. Moreover, activation of angiotensin II type 1 receptor (AT1R) in PVAT promotes vascular inflammation and endothelial dysfunction [147].
Sirtuin-3 (SIRT3), a mitochondrial $\mathrm{NAD}^{+}$-dependent deacetylase that regulates multiple metabolic enzymes, plays a significant role in Ang II-related PVAT inflammation. It was reported that Ang II promotes PVAT inflammation and fibrosis by stimulating NLRP3/IL-I $\beta$ pathway in myeloid SIRT3 knockout mice [148]. Activation of NLRP3 inflammasome is involved in vascular inflammation and its blockade has been proven to reduce adipose tissue inflammation and fibrosis (P. [149, 150]). SIRT3 is therefore a potential therapeutic target to inhibit NLRP3-related PVAT inflammation and fibrosis [148].

In addition to the direct actions of Ang II, aldosterone that is released in response to Ang II stimulation also has a proinflammatory action on PVAT [151]. Treatment with aldosterone receptor antagonists improves endothelial function, reduces oxidative stress, and decreases blood pressure $[152,153]$. Meanwhile, treatment with angiotensin receptor blockers lower the release of Ang II from PVAT. This leads 
TABLE 2: Changes related to PVAT inflammation in atherosclerosis and hypertension.

\begin{tabular}{|c|c|}
\hline Atherosclerosis & Hypertension \\
\hline $\begin{array}{l}\text { (i) } \uparrow \text { MCP-1 [197] } \\
\end{array}$ & (i) $\uparrow$ IL-6, IL-17, IL-8, IL-23, IL-1 $\beta$, TNF- $\alpha$, TGF- $\beta$, MCP-1 [198-200] \\
\hline (ii) $\uparrow$ RANTES [201] & (ii) $\downarrow$ adiponectin, IL-10, IL-4 [202] \\
\hline (iii) $\uparrow$ IL-6, IL-1, IL-7 [203-205] & (iii) $\uparrow$ RAAS, aldosterone, and Ang II [206] \\
\hline (iv) $\uparrow$ TNF- $\alpha[207]$ & (iv) $\uparrow$ activation of AT1R [208] \\
\hline (v) $\downarrow$ adiponectin [209] & (v) $\uparrow \operatorname{ROS}[210]$ \\
\hline (vi) $\uparrow$ Xpr1 \& Taf3 [111] & (vi) $\uparrow$ NOX [211] \\
\hline (vii) $\uparrow$ PIAS1 [212] & (vii) $\uparrow$ complement C3 [213] \\
\hline (viii) $\uparrow$ FFA [214] & (viii) $\uparrow$ CCR2, CCL2, CCL7, CCL8, CCL12, CCL3 [140] \\
\hline (ix) $\uparrow$ ROS [215] & (ix) $\uparrow$ ET-1 [210] \\
\hline \multicolumn{2}{|l|}{$(\mathrm{x}) \downarrow \mathrm{NO}[216]$} \\
\hline \multicolumn{2}{|l|}{ (xi) $\downarrow \mathrm{H}_{2} \mathrm{~S}[217]$} \\
\hline \multicolumn{2}{|l|}{ (xii) $\uparrow$ IFN- $\gamma$ [218] } \\
\hline \multicolumn{2}{|l|}{ (xiii) $\uparrow$ Leptin [219] } \\
\hline (xiv) $\uparrow$ Visfatin [220] & \\
\hline
\end{tabular}

$(\mathrm{xv}) \uparrow \operatorname{MIP}-1 \alpha[221]$

(xvi) $\downarrow \operatorname{IgM}[222]$

Abbreviations: Ang II: angiotensin II; AT1R: angiotensin II type 1 receptor; C3: component 3; CCR: CC chemokine receptor; CCL: CC chemokine ligand; ET1: endothelin-1; FFA: free fatty acid; $\mathrm{H}_{2} \mathrm{~S}$ : hydrogen sulfide; IFN- $\gamma$ : interferon- $\gamma$; IL: interleukin; IgM: immunoglobulin M; MCP-1: monocyte chemoattractant protein-1; MIP-1 $\alpha$ : macrophage inflammatory protein $1-\alpha$; NO: nitric oxide; NOX: NADPH oxidase; PIAS1: protein inhibitor of activated STAT1; RAAS: renin-angiotensin-aldosterone system; RANTES: regulated on activation, normal T cell expressed, and secreted; ROS: reactive oxygen species; Taf3: TATA-box binding protein-associated factor 3; TNF- $\alpha$ : tumor necrosis factor-alpha; Xpr1: xenotropic and polytropic retrovirus receptor 1.

to the release of PVAT-derived relaxing factors that stimulate vasodilation through the opening of voltage-gated potassium channels in the vascular smooth muscle cells [147, 154, 155].

A complex reactive oxygen species (ROS) machinery containing NADPH oxidase (Nox) and antioxidative enzymes are also expressed in PVAT [156, 157]. Chronic oxidative stress enhances vascular inflammation in hypertension, with Nox being the main source of superoxide in the vasculature [158]. ROS derived from Nox in PVAT induces endothelial dysfunction by scavenging endothelial NO and modulating perivascular inflammation [90, 159].

SHR showed greater $\mathrm{T}$ cell accumulation in the PVAT and higher mRNA expression of Nox1 and Nox 4 in the vessels, an effect that was exacerbated with aging [160]. Mice with the overexpression of Nox p22phox catalytic subunit have enhanced vascular superoxide production and increased PVAT leukocyte infiltration that worsens hypertension progression [161]. Meanwhile, mice with loss of Nox subunit such as p47phox, Nox1, and Nox4 show protection against hypertension $[162,163]$. Surprisingly, treatment of SHR with GKT137831, a dual inhibitor of Nox1/4, raised both blood pressure and PVAT macrophage infiltration and accelerated vascular aging. This observation was associated with increased expression of proinflammatory chemokine expression (CCL2 and CCL5) in the PVAT [160]. Therefore, these changes need to be considered when designing a therapy that targets Nox to treat hypertension.
Hypertension is more common in people who are obese compared to people who are lean [164]. Animal studies showed that obesity leads to increased PVAT mass and adipocyte hypertrophy with signs of PVAT inflammation, endothelial dysfunction, and altered release of adipocytokines. The release of proinflammatory cytokines such as TNF- $\alpha$, MCP1 , IL-6, and IL- 8 is markedly enhanced, whereas the antiinflammatory adipokine, adiponectin, is markedly reduced [90, 91]. TNF- $\alpha$ inhibits adiponectin and NO production and stimulates ET-1 release. Imbalance between the vasoconstrictor ET-1 and the vasodilators such as NO and adiponectin is implicated in obesity-induced endothelial dysfunction and hypertension [42]. Adiponectin level is restored in hypertensive patients who received antihypertensive agents to control their blood pressure, which signifies the beneficial effect of adiponectin in hypertension [165].

PVAT inflammation and altered adipocytokine profile in obesity have significant effects on the anticontractile effect of PVAT and blood pressure [166]. Obesity causes the loss of anticontractile function of PVAT [90] and impairs endothelium-dependent vasorelaxation which contribute to hypertension [167]. The loss of anticontractile function of PVAT correlates with the increase in blood pressure in rodent models of diet-induced obesity [87]. Like obese animal models, the anticontractile effect of PVAT is lost in obese patients [168]. TNF- $\alpha$ expression is also elevated in the vascular wall and PVAT isolated from the small arteries of obese patients [42]. Six months following bariatric surgery, reduction in the body 
weight of obese patients is accompanied by improvement in their PVAT adipocytokine profile, PVAT anticontractile function, and blood pressure [168]. The mechanisms linking PVAT inflammation and hypertension are summarized in Figure 3.

\section{Conclusion}

PVAT inflammation plays a mechanistic role in the pathogenesis of vascular diseases such as atherosclerosis and hypertension (Table 2). The vicinity of PVAT as an active endocrine and paracrine organ that produces various adipocytokines as well as the related changes in this tissue supports the idea that alteration in PVAT phenotype contributes to disease processes in the adjacent vascular wall. Inflammation leads to PVAT dysfunction through the release of various proinflammatory adipocytokines and immune cell infiltration. Although the mechanisms on how PVAT inflammation is linked to vascular diseases are not entirely clear, hence the need for more mechanistic studies to explore this matter, the available evidence shows that PVAT inflammation occurs at the initial part of vascular pathology in a tightly regulated manner. Therefore, further studies are needed to explore the potential of PVAT as a target for the prevention and treatment of vascular diseases.

\section{Conflicts of Interest}

The authors declare no conflict of interest.

\section{Acknowledgments}

This project is supported by the Faculty of Medicine, Universiti Kebangsaan Malaysia (project code FF-2021-146).

\section{References}

[1] World Health Organization, "Cardiovascular Diseases (CVD)," 2021, https://www.who.int/news-room/fact-sheets/ detail/cardiovascular-diseases-(cvds).

[2] E. Okamoto, T. Couse, H. de Leon et al., "Perivascular inflammation after balloon angioplasty of porcine coronary arteries," Circulation, vol. 104, no. 18, pp. 2228-2235, 2001.

[3] S. N. Saxton, A. M. Heagerty, and S. B. Withers, "Perivascular adipose tissue: an immune cell metropolis," Experimental Physiology, vol. 105, no. 9, pp. 1440-1443, 2020.

[4] M. S. Fernández-Alfonso, B. Somoza, D. Tsvetkov, A. Kuczmanski, M. Dashwood, and M. Gil-Ortega, "Role of perivascular adipose tissue in health and disease," in Comprehensive Physiology, pp. 23-59, 2017.

[5] K.-V. Tran, T. Fitzgibbons, S. Y. Min, T. DeSouza, and S. Corvera, "Distinct adipocyte progenitor cells are associated with regional phenotypes of perivascular aortic fat in mice," Molecular Metabolism, vol. 9, pp. 199-206, 2018.

[6] W. Xiong, X. Zhao, L. Villacorta et al., "Brown AdipocyteSpecific PPAR $\gamma$ (Peroxisome Proliferator-Activated Receptor $\gamma$ ) deletion impairs Perivascular Adipose Tissue development and enhances atherosclerosis in mice," Arteriosclerosis, Thrombosis, and Vascular Biology, vol. 38, no. 8, pp. 17381747, 2018.

[7] X. Y. Qi, S. L. Qu, W. H. Xiong, O. Rom, L. Chang, and Z. S. Jiang, "Perivascular adipose tissue (PVAT) in atherosclerosis: a double-edged sword," Cardiovascular Diabetology, vol. 17, no. 1, p. $134,2018$.

[8] L. Chang, L. Villacorta, R. Li et al., "Loss of perivascular adipose tissue on peroxisome proliferator-activated receptor- $\gamma$ deletion in smooth muscle cells impairs intravascular thermoregulation and enhances atherosclerosis," Circulation, vol. 126, no. 9, pp. 1067-1078, 2012.

[9] S. Hildebrand, J. Stümer, and A. Pfeifer, "PVAT and Its Relation to Brown, Beige, and White Adipose Tissue in Development and Function," Frontiers in Physiology, vol. 9, p. 70, 2018.

[10] V. Pellegrinelli, S. Carobbio, and A. Vidal-Puig, "Adipose tissue plasticity: how fat depots respond differently to pathophysiological cues," Diabetologia, vol. 59, no. 6, pp. 1075$1088,2016$.

[11] I. Akoumianakis, A. Tarun, and C. Antoniades, "Perivascular adipose tissue as a regulator of vascular disease pathogenesis: identifying novel therapeutic targets," British Journal of Pharmacology, vol. 174, no. 20, pp. 3411-3424, 2017.

[12] A. Grigoras, C. Amalinei, R. A. Balan, S. E. Giusca, and I. D. Caruntu, "Perivascular adipose tissue in cardiovascular diseases-an update," Anatolian Journal of Cardiology, vol. 22, no. 5, pp. 219-231, 2019.

[13] M. J. Hobson, P. W. Hake, M. O’Connor et al., "Conditional deletion of cardiomyocyte peroxisome proliferator-activated receptor $\gamma$ enhances myocardial ischemia-reperfusion injury in mice," Shock (Augusta, Ga.), vol. 41, no. 1, pp. 40-47, 2014.

[14] J. Y. Chen, Y. P. Wu, C. Y. Li et al., "PPAR $\gamma$ activation improves the microenvironment of perivascular adipose tissue and attenuates aortic stiffening in obesity," Journal of Biomedical Science, vol. 28, no. 1, p. 22, 2021.

[15] T. P. Mikołajczyk and T. J. Guzik, "Perivascular adipose tissue as the secret behind resistance to atherosclerosis exhibited by the human internal mammary artery," Kardiologia Polska, vol. 78, no. 12, pp. 1194-1196, 2020.

[16] A. Sowka and P. Dobrzyn, "Role of perivascular adipose tissue-derived adiponectin in vascular homeostasis," Cells, vol. 10, no. 6, p. 1485, 2021.

[17] S. B. Withers, C. E. Bussey, S. N. Saxton, H. M. Melrose, A. E. Watkins, and A. M. Heagerty, "Mechanisms of adiponectinassociated perivascular function in vascular disease," Arteriosclerosis, Thrombosis, and Vascular Biology, vol. 34, no. 8, pp. 1637-1642, 2014.

[18] R. Nosalski and T. J. Guzik, "Perivascular adipose tissue inflammation in vascular disease," British Journal of Pharmacology, vol. 174, no. 20, pp. 3496-3513, 2017.

[19] J. G. Ramirez, E. J. O'Malley, and W. S. V. Ho, "Pro-contractile effects of perivascular fat in health and disease," British Journal of Pharmacology, vol. 174, no. 20, pp. 3482-3495, 2017.

[20] H. Yanai and H. Yoshida, "Beneficial effects of adiponectin on glucose and lipid metabolism and atherosclerotic progression: mechanisms and perspectives," International Journal of Molecular Sciences, vol. 20, no. 5, p. 1190, 2019.

[21] S. Feijóo-Bandín, A. Aragón-Herrera, S. Moraña-Fernández et al., "Adipokines and inflammation: focus on cardiovascular diseases," International Journal of Molecular Sciences, vol. 21, no. 20, pp. 7711-7734, 2020.

[22] J. Zhang, L. Xia, F. Zhang et al., "A novel mechanism of diabetic vascular endothelial dysfunction: hypoadiponectinemiainduced NLRP3 inflammasome activation," Biochimica et Biophysica Acta-Molecular Basis of Disease, vol. 1863, no. 6, pp. 1556-1567, 2017. 
[23] Y. Hou, X. F. Wang, Z. Q. Lang et al., “Adiponectin is protective against endoplasmic reticulum stress-induced apoptosis of endothelial cells in sepsis," Brazilian Journal of Medical and Biological Research = Revista Brasileira de Pesquisas Medicas e Biologicas, vol. 51, no. 12, article e7747, 2018.

[24] H. Zhou, Z. Zhang, G. Qian, and J. Zhou, "Omentin-1 attenuates adipose tissue inflammation via restoration of TXNIP/ NLRP3 signaling in high-fat diet-induced obese mice," Fundamental \& Clinical Pharmacology, vol. 34, no. 6, pp. 721735, 2020.

[25] J. Wang, Y. Gao, F. Lin, K. Han, and X. Wang, “Omentin-1 attenuates lipopolysaccharide (LPS)-induced U937 macrophages activation by inhibiting the TLR4/MyD88/NF- $\kappa \mathrm{B}$ signaling," Archives of Biochemistry and Biophysics, vol. 679, article 108187, 2020.

[26] F. Liu, S. Fang, X. Liu et al., "Omentin-1 protects against high glucose-induced endothelial dysfunction via the AMPK/ PPAR $\delta$ signaling pathway," Biochemical Pharmacology, vol. 174, article 113830, 2020.

[27] H. Yamawaki, J. Kuramoto, S. Kameshima, T. Usui, M. Okada, and Y. Hara, "Omentin, a novel adipocytokine inhibits TNF-induced vascular inflammation in human endothelial cells," Biochemical and Biophysical Research Communications, vol. 408, no. 2, pp. 339-343, 2011.

[28] F. M. Fisher and E. Maratos-Flier, "Understanding the physiology of FGF21," Annual Review of Physiology, vol. 78, no. 1, pp. 223-241, 2016.

[29] N. Wang, J. Y. Li, S. Li et al., "Fibroblast growth factor 21 regulates foam cells formation and inflammatory response in Ox-LDL-induced THP-1 macrophages," Biomedicine \& Pharmacotherapy = Biomedecine \& Pharmacotherapie, vol. 108, pp. 1825-1834, 2018.

[30] N. Wang, T. T. Zhao, S. M. Li et al., "Fibroblast growth factor 21 exerts its anti-inflammatory effects on multiple cell types of adipose tissue in obesity," Obesity (Silver Spring, Md.), vol. 27, no. 3, pp. 399-408, 2019.

[31] X. Wu, Y. F. Qi, J. R. Chang et al., "Possible role of fibroblast growth factor 21 on atherosclerosis via amelioration of endoplasmic reticulum stress-mediated apoptosis in apoE(-/-) mice," Heart and Vessels, vol. 30, no. 5, pp. 657-668, 2015.

[32] X. Yan, Z. Gou, Y. Li et al., "Fibroblast growth factor 21 inhibits atherosclerosis in apoE-/- mice by ameliorating Fas-mediated apoptosis," Lipids in Health and Disease, vol. 17, no. 1, p. 203, 2018.

[33] Z. Zeng, Q. Zheng, J. Chen et al., "FGF21 mitigates atherosclerosis via inhibition of NLRP3 inflammasome-mediated vascular endothelial cells pyroptosis," Experimental Cell Research, vol. 393, no. 2, article 112108, 2020.

[34] L. Ying, N. Li, Z. He et al., "Fibroblast growth factor 21 ameliorates diabetes-induced endothelial dysfunction in mouse aorta via activation of the CaMKK2/AMPK $\alpha$ signaling pathway," Cell Death \& Disease, vol. 10, no. 9, p. 665, 2019.

[35] K. I. Maijer, E. Neumann, U. Müller-Ladner et al., "Serum vaspin levels are associated with the development of clinically manifest arthritis in autoantibody-positive individuals," PLoS One, vol. 10, no. 12, article e0144932, 2015.

[36] J. Bao, L. H. Xu, J. S. Ran, Y. Xiong, and L. D. Wu, "Vaspin prevents leptin-induced inflammation and catabolism by inhibiting the activation of nuclear factor- $\kappa \mathrm{B}$ in rat chondrocytes," Molecular Medicine Reports, vol. 16, no. 3, pp. 29252930, 2017.
[37] S. S. Iyer, A. A. Ghaffari, and G. Cheng, "Lipopolysaccharidemediated IL-10 transcriptional regulation requires sequential induction of type I IFNs and IL-27 in macrophages," Journal of Immunology (Baltimore, Md. : 1950), vol. 185, no. 11, pp. 6599-6607, 2010.

[38] T. J. Guzik, D. S. Skiba, R. M. Touyz, and D. G. Harrison, "The role of infiltrating immune cells in dysfunctional adipose tissue," Cardiovascular Research, vol. 113, no. 9, pp. 1009-1023, 2017.

[39] S. S. Iyer and G. Cheng, "Role of interleukin 10 transcriptional regulation in inflammation and autoimmune disease," Critical Reviews in Immunology, vol. 32, no. 1, pp. 23-63, 2012.

[40] U. M. Sundar, A. Ugusman, H. K. Chua, J. Latip, and A. Aminuddin, "Piper sarmentosum promotes endothelial nitric oxide production by reducing asymmetric dimethylarginine in tumor necrosis factor- $\alpha$-induced human umbilical vein endothelial cells," Frontiers in Pharmacology, vol. 10, p. 1033, 2019.

[41] U. Forstermann and W. C. Sessa, "Nitric oxide synthases: regulation and function," European Heart Journal, vol. 33, no. 7, pp. 829-837, 2012.

[42] A. Virdis, E. Duranti, C. Rossi et al., "Tumour necrosis factoralpha participates on the endothelin-1/nitric oxide imbalance in small arteries from obese patients: role of perivascular adipose tissue," European Heart Journal, vol. 36, no. 13, pp. 784794, 2015.

[43] J. H. Lim, H. J. Um, J. W. Park, I. K. Lee, and T. K. Kwon, "Interleukin- $1 \beta$ promotes the expression of monocyte chemoattractant protein-1 in human aorta smooth muscle cells via multiple signaling pathways," Experimental \& Molecular Medicine, vol. 41, no. 10, pp. 757-764, 2009.

[44] N. Kaneko, M. Kurata, T. Yamamoto, S. Morikawa, and J. Masumoto, "The role of interleukin-1 in general pathology," Inflammation and Regeneration, vol. 39, no. 1, p. 12, 2019.

[45] J. L. Rourke, H. J. Dranse, and C. J. Sinal, “Towards an integrative approach to understanding the role of chemerin in human health and disease," Obesity Reviews, vol. 14, no. 3, pp. 245-262, 2013.

[46] C. G. Kostopoulos, S. G. Spiroglou, J. N. Varakis, E. Apostolakis, and H. H. Papadaki, "Chemerin and CMKLR1 expression in human arteries and periadventitial fat: a possible role for local chemerin in atherosclerosis?," BMC Cardiovascular Disorders, vol. 14, no. 1, p. 56, 2014.

[47] S. Zylla, M. Pietzner, J. P. Kühn et al., "Serum chemerin is associated with inflammatory and metabolic parametersresults of a population-based study," Obesity (Silver Spring, Md.), vol. 25, no. 2, pp. 468-475, 2017.

[48] V. Catalán, J. Gómez-Ambrosi, A. Rodríguez et al., "Increased levels of chemerin and its receptor, chemokinelike receptor-1, in obesity are related to inflammation: tumor necrosis factor- $\alpha$ stimulates mRNA levels of chemerin in visceral adipocytes from obese patients," Surgery for Obesity and Related Diseases, vol. 9, no. 2, pp. 306-314, 2013.

[49] A. R. Ghosh, R. Bhattacharya, S. Bhattacharya et al., "Adipose Recruitment and Activation of Plasmacytoid Dendritic Cells Fuel Metaflammation," Diabetes, vol. 65, no. 11, pp. 34403452, 2016.

[50] R. Hart and D. R. Greaves, "Chemerin contributes to inflammation by promoting macrophage adhesion to VCAM-1 and fibronectin through clustering of VLA-4 and VLA-5," Journal of Immunology (Baltimore, Md. : 1950), vol. 185, no. 6, pp. 3728-3739, 2010. 
[51] K. Sawicka, M. Michalska-Jakubus, E. Potembska, M. Kowal, A. Pietrzak, and D. Krasowska, "Visfatin and chemerin levels correspond with inflammation and might reflect the bridge between metabolism, inflammation and fibrosis in patients with systemic sclerosis," Postepy Dermatologii i Alergologii, vol. 36, no. 5, pp. 551-565, 2019.

[52] O. Gruzdeva, D. Borodkina, E. Uchasova, Y. Dyleva, and O. Barbarash, "Leptin resistance: underlying mechanisms and diagnosis," Diabetes, Metabolic Syndrome and Obesity: Targets and Therapy, vol. 12, pp. 191-198, 2019.

[53] B. Liu, J. Qiao, J. Hu et al., "Leptin promotes endothelial dysfunction in chronic kidney disease by modulating the MTA1mediated WNT/ $\beta$-catenin pathway," Molecular and Cellular Biochemistry, vol. 473, no. 1-2, pp. 155-166, 2020.

[54] I. Drosos, G. Chalikias, M. Pavlaki et al., "Differences between perivascular adipose tissue surrounding the heart and the internal mammary artery: possible role for the leptin-inflammation-fibrosis-hypoxia axis," Clinical Research in Cardiology, vol. 105, no. 11, pp. 887-900, 2016.

[55] M. Bokarewa, I. Nagaev, L. Dahlberg, U. Smith, and A. Tarkowski, "Resistin, an adipokine with potent proinflammatory properties," Journal of Immunology (Baltimore, Md. : 1950), vol. 174, no. 9, pp. 5789-5795, 2005.

[56] C. Chen, J. Jiang, J. M. Lü et al., "Resistin decreases expression of endothelial nitric oxide synthase through oxidative stress in human coronary artery endothelial cells," American Journal of Physiology-Heart and Circulatory Physiology, vol. 299, no. 1, pp. H193-H201, 2010.

[57] J. Luo, L. Huang, A. Wang et al., "Resistin-induced endoplasmic reticulum stress contributes to the impairment of insulin signaling in endothelium," Frontiers in Pharmacology, vol. 9, p. 1226, 2018.

[58] R. S. de Lima, J. C. . S. Silva, C. T. Lima et al., "Proinflammatory role of angiotensin II in the aorta of normotensive mice," BioMed Research International, vol. 2019, Article ID 9326896, 11 pages, 2019.

[59] H. Pons, A. Ferrebuz, Y. Quiroz et al., "Immune reactivity to heat shock protein 70 expressed in the kidney is cause of saltsensitive hypertension," American Journal of Physiology Renal Physiology, vol. 304, no. 3, pp. F289-F299, 2013.

[60] B. Rodriguez-Iturbe, "Autoimmunity in the pathogenesis of hypertension," Hypertension, vol. 67, no. 3, pp. 477-483, 2016.

[61] T. P. Mikolajczyk, R. Nosalski, P. Szczepaniak et al., "Role of chemokine RANTES in the regulation of perivascular inflammation, T-cell accumulation, and vascular dysfunction in hypertension," FASEB Journal, vol. 30, no. 5, pp. 1987-1999, 2016.

[62] L. Markó, H. Kvakan, J. K. Park et al., "Interferon- $\gamma$ signaling inhibition ameliorates angiotensin II-induced cardiac damage," Hypertension (Dallas, Tex. : 1979), vol. 60, no. 6, pp. 1430-1436, 2012.

[63] P. Libby, J. E. Buring, L. Badimon et al., "Atherosclerosis," Nature Reviews Disease Primers, vol. 5, no. 1, p. 56, 2019.

[64] A. Chroni, G. Leondaritis, and H. Karlsson, "Lipids and lipoproteins in atherosclerosis," Journal of Lipids, vol. 2011, Article ID 160104, 2 pages, 2011.

[65] M. Rafieian-Kopaei, M. Setorki, M. Doudi, A. Baradaran, and H. Nasri, "Atherosclerosis: process, indicators, risk factors and new hopes," International Journal of Preventive Medicine, vol. 5, no. 8, pp. 927-946, 2014.

[66] D. Tousoulis, E. Oikonomou, E. K. Economou, F. Crea, and J. C. Kaski, "Inflammatory cytokines in atherosclerosis: cur- rent therapeutic approaches," European Heart Journal, vol. 37, no. 22, pp. 1723-1732, 2016.

[67] E. Nava and S. Llorens, "The local regulation of vascular function: from an inside-outside to an outside-inside model," Frontiers in Physiology, vol. 10, p. 729, 2019.

[68] T. K. Chatterjee, L. L. Stoll, G. M. Denning et al., "Proinflammatory phenotype of perivascular adipocytes: influence of high-fat feeding," Circulation Research, vol. 104, no. 4, pp. 541-549, 2009.

[69] J. Mancio, E. K. Oikonomou, and C. Antoniades, "Perivascular adipose tissue and coronary atherosclerosis," Heart (British Cardiac Society), vol. 104, no. 20, pp. 1654-1662, 2018.

[70] A. Omar, T. K. Chatterjee, Y. Tang, D. Y. Hui, and N. L. Weintraub, "Proinflammatory phenotype of perivascular adipocytes," Arteriosclerosis, Thrombosis, and Vascular Biology, vol. 34, no. 8, pp. 1631-1636, 2014.

[71] D. S. Skiba, R. Nosalski, T. P. Mikolajczyk et al., "Anti-atherosclerotic effect of the angiotensin 1-7 mimetic AVE0991 is mediated by inhibition of perivascular and plaque inflammation in early atherosclerosis," British Journal of Pharmacology, vol. 174, no. 22, pp. 4055-4069, 2017.

[72] T. K. Chatterjee, B. J. Aronow, W. S. Tong et al., "Human coronary artery perivascular adipocytes overexpress genes responsible for regulating vascular morphology, inflammation, and hemostasis," Physiological Genomics, vol. 45, no. 16, pp. 697-709, 2013.

[73] A. Virdis, "Endothelial dysfunction in obesity: role of inflammation," High Blood Pressure \& Cardiovascular Prevention, vol. 23, no. 2, pp. 83-85, 2016.

[74] H. Wu, S. Ghosh, X. D. Perrard et al., "T-cell accumulation and regulated on activation, normal $\mathrm{T}$ cell expressed and secreted upregulation in adipose tissue in obesity," Circulation, vol. 115, no. 8, pp. 1029-1038, 2007.

[75] T. J. Guzik, N. E. Hoch, K. A. Brown et al., "Role of the T cell in the genesis of angiotensin II induced hypertension and vascular dysfunction," The Journal of Experimental Medicine, vol. 204, no. 10, pp. 2449-2460, 2007.

[76] P. Lesnik, C. A. Haskell, and I. F. Charo, "Decreased atherosclerosis in CX3CR1-/- mice reveals a role for fractalkine in atherogenesis," The Journal of Clinical Investigation, vol. 111, no. 3, pp. 333-340, 2003.

[77] S. Sakaguchi, M. Miyara, C. M. Costantino, and D. A. Hafler, "FOXP $3^{+}$regulatory T cells in the human immune system," Nature Reviews Immunology, vol. 10, no. 7, pp. 490-500, 2010.

[78] H. A. Itani, W. G. McMaster Jr., M. A. Saleh et al., "Activation of Human T Cells in Hypertension: Studies of Humanized Mice and Hypertensive Humans," Hypertension (Dallas, Tex. : 1979), vol. 68, no. 1, pp. 123-132, 2016.

[79] D. A. Kasal, T. Barhoumi, M. W. Li et al., "T regulatory lymphocytes prevent aldosterone-induced vascular injury," Hypertension (Dallas, Tex. : 1979), vol. 59, no. 2, pp. 324330, 2012.

[80] L. Wu, V. V. Parekh, C. L. Gabriel et al., "Activation of invariant natural killer $\mathrm{T}$ cells by lipid excess promotes tissue inflammation, insulin resistance, and hepatic steatosis in obese mice," Proceedings of the National Academy of Sciences of the United States of America, vol. 109, no. 19, pp. E1143E1152, 2012.

[81] A. Ugusman, J. Kumar, and A. Aminuddin, "Endothelial function and dysfunction: Impact of sodium-glucose 
cotransporter 2 inhibitors," Pharmacology \& Therapeutics, vol. 224, article 107832, 2021.

[82] J. Chen, Z. X. Ye, X. F. Wang et al., "Nitric oxide bioavailability dysfunction involves in atherosclerosis," Biomedicine \& Pharmacotherapy, vol. 97, pp. 423-428, 2018.

[83] M. Mudau, A. Genis, A. Lochner, and H. Strijdom, "Endothelial dysfunction: the early predictor of atherosclerosis," Cardiovascular Journal of Africa, vol. 23, no. 4, pp. 222-231, 2012.

[84] M. Gil-Ortega, B. Somoza, Y. Huang, M. Gollasch, and M. S. Fernández-Alfonso, "Regional differences in perivascular adipose tissue impacting vascular homeostasis," Trends in Endocrinology \& Metabolism, vol. 26, no. 7, pp. 367-375, 2015.

[85] Z. J. Wang, J. Wu, W. Guo, and Y. Z. Zhu, "Atherosclerosis and the hydrogen sulfide signaling pathway - therapeutic approaches to disease prevention," Cellular Physiology and Biochemistry, vol. 42, no. 3, pp. 859-875, 2017.

[86] C. Agabiti-Rosei, C. de Ciuceis, C. Rossini et al., "Anticontractile activity of perivascular fat in obese mice and the effect of long-term treatment with melatonin," Journal of Hypertension, vol. 32, no. 6, pp. 1264-1274, 2014.

[87] R. Aghamohammadzadeh, R. D. Unwin, A. S. Greenstein, and A. M. Heagerty, "Effects of obesity on perivascular adipose tissue vasorelaxant function: nitric oxide, inflammation and elevated systemic blood pressure," Journal of Vascular Research, vol. 52, no. 5, pp. 299-305, 2015.

[88] T. Almabrouk, A. D. White, A. B. Ugusman et al., "High fat diet attenuates the anticontractile activity of aortic PVAT via a mechanism involving AMPK and reduced adiponectin secretion," Frontiers in Physiology, vol. 9, p. 51, 2018.

[89] J. Bełtowski, "Endogenous hydrogen sulfide in perivascular adipose tissue: role in the regulation of vascular tone in physiology and pathology," Canadian Journal of Physiology and Pharmacology, vol. 91, no. 11, pp. 889-898, 2013.

[90] J. Ketonen, J. Shi, E. Martonen, and E. Mervaala, "Periadventitial adipose tissue promotes endothelial dysfunction via oxidative stress in diet-induced obese $\mathrm{C} 57 \mathrm{Bl} / 6$ mice," Circulation Journal, vol. 74, no. 7, pp. 1479-1487, 2010.

[91] C. Marchesi, T. Ebrahimian, O. Angulo, P. Paradis, and E. L. Schiffrin, "Endothelial nitric oxide synthase uncoupling and perivascular adipose oxidative stress and inflammation contribute to vascular dysfunction in a rodent model of metabolic syndrome," Hypertension (Dallas, Tex. : 1979), vol. 54, no. 6, pp. 1384-1392, 2009.

[92] H. Hu, M. Garcia-Barrio, Z. S. Jiang, Y. E. Chen, and L. Chang, "Roles of perivascular adipose tissue in hypertension and atherosclerosis," Antioxidants and Redox Signaling, vol. 34, no. 9, pp. 736-749, 2021.

[93] M. Federici, A. Pandolfi, E. A. de Filippis et al., "G972R IRS-1 variant impairs insulin regulation of endothelial nitric oxide synthase in cultured human Endothelial cells," Circulation, vol. 109, no. 3, pp. 399-405, 2004.

[94] P. Geraldes and G. L. King, "Activation of protein kinase C isoforms and its impact on diabetic complications," Circulation Research, vol. 106, no. 8, pp. 1319-1331, 2010.

[95] M. Barton, "Prevention and endothelial therapy of coronary artery disease," Current Opinion in Pharmacology, vol. 13, no. 2, pp. 226-241, 2013.

[96] N. D. Brunetti, G. Salvemini, A. Cuculo et al., "Coronary artery ectasia is related to coronary slow flow and inflamma- tory activation," Atherosclerosis, vol. 233, no. 2, pp. 636-640, 2014.

[97] A. Zernecke and C. Weber, "Chemokines in the vascular inflammatory response of atherosclerosis," Cardiovascular Research, vol. 86, no. 2, pp. 192-201, 2010.

[98] I. Tabas, G. García-Cardeña, and G. K. Owens, "Recent insights into the cellular biology of atherosclerosis," The Journal of Cell Biology, vol. 209, no. 1, pp. 13-22, 2015.

[99] C.-Y. Miao and Z. Y. Li, "The role of perivascular adipose tissue in vascular smooth muscle cell growth," British Journal of Pharmacology, vol. 165, no. 3, pp. 643-658, 2012.

[100] K. T. Moe, T. M. Naylynn, N. O. Yin et al., "Tumor necrosis factor- $\alpha$ induces aortic intima-media thickening via perivascular adipose tissue inflammation," Journal of Vascular Research, vol. 50, no. 3, pp. 228-237, 2013.

[101] Z. Ding, A. M. Mizeracki, C. Hu, and J. L. Mehta, "LOX-1 deletion and macrophage trafficking in atherosclerosis," Biochemical and Biophysical Research Communications, vol. 440, no. 2, pp. 210-214, 2013.

[102] A. Yamashita, K. Shoji, T. Tsuruda et al., "Medial and adventitial macrophages are associated with expansive atherosclerotic remodeling in rabbit femoral artery," Histology and Histopathology, vol. 23, no. 2, pp. 127-136, 2008.

[103] D. Manka, T. K. Chatterjee, L. L. Stoll et al., “Transplanted perivascular adipose tissue accelerates injury-induced neointimal hyperplasia: role of monocyte chemoattractant protein1," Arteriosclerosis, Thrombosis, and Vascular Biology, vol. 34, no. 8, pp. 1723-1730, 2014.

[104] M. P. W. Moos, N. John, R. Gräbner et al., “The lamina adventitia is the major site of immune cell accumulation in standard chow-fed apolipoprotein E-Deficient mice," Arteriosclerosis, Thrombosis, and Vascular Biology, vol. 25, no. 11, pp. 2386-2391, 2005.

[105] S. Sakamoto, T. Tsuruda, K. Hatakeyama, T. Imamura, Y. Asada, and K. Kitamura, "Impact of age-dependent adventitia inflammation on structural alteration of abdominal aorta in hyperlipidemic mice," PLoS One, vol. 9, no. 8, article e105739, 2014.

[106] C. Lohmann, N. Schäfer, T. von Lukowicz et al., "Atherosclerotic mice exhibit systemic inflammation in periadventitial and visceral adipose tissue, liver, and pancreatic islets," Atherosclerosis, vol. 207, no. 2, pp. 360-367, 2009.

[107] P. Srikakulapu, A. Upadhye, F. Drago et al., "Chemokine receptor- 6 promotes B-1 cell trafficking to perivascular adipose tissue, local IgM production and atheroprotection," Frontiers in Immunology, vol. 12, pp. 1-13, 2021.

[108] C. Li, S. Li, F. Zhang et al., "Endothelial microparticlesmediated transfer of microRNA-19b promotes atherosclerosis via activating perivascular adipose tissue inflammation in apoE $^{-1-}$ mice," Biochemical and Biophysical Research Communications, vol. 495, no. 2, pp. 1922-1929, 2017.

[109] K. Terada, H. Yamada, M. Kikai et al., "Transplantation of periaortic adipose tissue inhibits atherosclerosis in $a p o E^{-1-}$ mice by evoking TGF- $\beta 1$-mediated anti- inflammatory response in transplanted graft," Biochemical and Biophysical Research Communications, vol. 501, no. 1, pp. 145151, 2018.

[110] C. Li, Z. Wang, C. Wang, Q. Ma, and Y. Zhao, "Perivascular adipose tissue-derived adiponectin inhibits collar-induced carotid atherosclerosis by promoting macrophage autophagy," PLoS One, vol. 10, no. 5, article e0124031, 2015. 
[111] M. Hueso, L. de Ramon, E. Navarro et al., "Silencing of CD40 in vivo reduces progression of experimental atherogenesis through an NF- $\kappa \mathrm{B} / \mathrm{miR}-125 \mathrm{~b}$ axis and reveals new potential mediators in the pathogenesis of atherosclerosis," Atherosclerosis, vol. 255, pp. 80-89, 2016.

[112] A. R. Baker, N. F. da Silva, D. W. Quinn et al., "Human epicardial adipose tissue expresses a pathogenic profile of adipocytokines in patients with cardiovascular disease," Cardiovascular Diabetology, vol. 5, no. 1, p. 1, 2006.

[113] G. Iacobellis, D. Pistilli, M. Gucciardo et al., "Adiponectin expression in human epicardial adipose tissue in vivo is lower in patients with coronary artery disease," Cytokine, vol. 29, no. 6, pp. 251-255, 2005.

[114] T. Mazurek, L. F. Zhang, A. Zalewski et al., "Human epicardial adipose tissue is a source of inflammatory mediators," Circulation, vol. 108, no. 20, pp. 2460-2466, 2003.

[115] T. Suzuki, H. Ogita, A. Sato, N. Minamidate, and K. Hachiro, "Differences between patients with and without atherosclerosis in expression levels of inflammatory mediators in the adipose tissue around the coronary artery," International Heart Journal, vol. 62, no. 2, pp. 390-395, 2021.

[116] E. Schütz, R. Gogiraju, M. Pavlaki et al., Age-Dependent and -Independent E ff ects of Perivascular Adipose Tissue and Its Paracrine Activities during Neointima Formation, pp. 1-20, 2020.

[117] B. Liu, J. Liao, X. Rao et al., "Inhibition of Stat1-mediated gene activation by PIAS1," Proceedings of the National Academy of Sciences of the United States of America, vol. 95, no. 18, pp. 10626-10631, 1998.

[118] B. Liu, R. Yang, K. A. Wong et al., "Negative regulation of NF-kappaB signaling by PIAS1," Molecular and Cellular Biology, vol. 25, no. 3, pp. 1113-1123, 2005.

[119] I. Kralova Lesna, Z. Tonar, I. Malek et al., "Is the amount of coronary perivascular fat related to atherosclerosis?," Physiological Research, vol. 64, Supplement 3, pp. S435S443, 2015.

[120] F. Tavora, R. Kutys, L. Li, M. Ripple, D. Fowler, and A. Burke, "Adventitial lymphocytic inflammation in human coronary arteries with intimal atherosclerosis," Cardiovascular Pathology, vol. 19, no. 3, pp. e61-e68, 2010.

[121] S. N. Verhagen, A. Vink, Y. van der Graaf, and F. L. J. Visseren, "Coronary perivascular adipose tissue characteristics are related to atherosclerotic plaque size and composition. A post-mortem study," Atherosclerosis, vol. 225, no. 1, pp. 99104, 2012.

[122] D. A. Chistiakov, A. N. Orekhov, and Y. V. Bobryshev, "Contribution of neovascularization and intraplaque haemorrhage to atherosclerotic plaque progression and instability," Acta Physiologica (Oxford, England), vol. 213, no. 3, pp. 539-553, 2015.

[123] D. S. Farias-Itao, C. A. Pasqualucci, A. Nishizawa et al., "B lymphocytes and macrophages in the perivascular adipose tissue are associated with coronary atherosclerosis: an autopsy study," Journal of the American Heart Association, vol. 8, no. 24, article e013793, 2019.

[124] N. Kawasaki, R. Asada, A. Saito, S. Kanemoto, and K. Imaizumi, "Obesity-induced endoplasmic reticulum stress causes chronic inflammation in adipose tissue," Scientific Reports, vol. 2, no. 1, p. 799, 2012.

[125] R. Ying, S. W. Li, J. Y. Chen et al., "Endoplasmic reticulum stress in perivascular adipose tissue promotes destabilization of atherosclerotic plaque by regulating GM-CSF paracrine," Journal of Translational Medicine, vol. 16, no. 1, pp. 1-13, 2018.

[126] D.-H. Kim, D. Sandoval, J. A. Reed et al., "The role of GMCSF in adipose tissue inflammation," American Journal of Physiology. Endocrinology and Metabolism, vol. 295, no. 5, pp. E1038-E1046, 2008.

[127] D. G. Harrison, T. J. Guzik, H. E. Lob et al., "Inflammation, immunity, and hypertension," Hypertension (Dallas, Tex. : 1979), vol. 57, no. 2, pp. 132-140, 2011.

[128] A. Kirabo, V. Fontana, A. P. C. de Faria et al., "DC isoketalmodified proteins activate $\mathrm{T}$ cells and promote hypertension," The Journal of Clinical Investigation, vol. 124, no. 10, pp. 4642-4656, 2014.

[129] D. M. Tanase, E. M. Gosav, S. Radu et al., "Arterial hypertension and interleukins: potential therapeutic target or future diagnostic marker?," International Journal of Hypertension, vol. 2019, Article ID 3159283, 17 pages, 2019.

[130] R. Supriya, B. Y. Yung, A. P. Yu et al., "Adipokine profiling in adult women with central obesity and hypertension," Frontiers in Physiology, vol. 9, p. 294, 2018.

[131] C.-C. Ruan, Y. Ma, Q. Ge et al., "Complement-mediated inhibition of adiponectin regulates perivascular inflammation and vascular injury in hypertension," FASEB Journal, vol. 31, no. 3, pp. 1120-1129, 2017.

[132] S. Kossmann, M. Schwenk, M. Hausding et al., “Angiotensin II-induced vascular dysfunction depends on interferon- $\gamma$ driven immune cell recruitment and mutual activation of monocytes and NK-cells," Arteriosclerosis, Thrombosis, and Vascular Biology, vol. 33, no. 6, pp. 1313-1319, 2013.

[133] L. Zou, W. Wang, S. Liu et al., "Spontaneous hypertension occurs with adipose tissue dysfunction in perilipin-1 null mice," Biochimica et Biophysica Acta, vol. 1862, no. 2, pp. 182-191, 2016.

[134] C.-C. Ruan, D. L. Zhu, Q. Z. Chen et al., "Perivascular adipose tissue-derived complement 3 is required for adventitial fibroblast functions and adventitial remodeling in deoxycorticosterone acetate-salt hypertensive rats," Arteriosclerosis, Thrombosis, and Vascular Biology, vol. 30, no. 12, pp. 25682574, 2010.

[135] C.-C. Ruan, Q. Ge, Y. Li et al., "Complement-mediated macrophage polarization in perivascular adipose tissue contributes to vascular injury in deoxycorticosterone acetate-salt mice," Arteriosclerosis, Thrombosis, and Vascular Biology, vol. 35, no. 3, pp. 598-606, 2015.

[136] T. Minami, K. Satoh, M. Nogi et al., "Statins up-regulate SmgGDS through $\beta 1$-integrin/Akt1 pathway in endothelial cells," Cardiovascular Research, vol. 109, no. 1, pp. 151-161, 2016.

[137] M. Nus, B. Martínez-Poveda, D. MacGrogan et al., "Endothelial Jag1-RBPJ signalling promotes inflammatory leucocyte recruitment and atherosclerosis," Cardiovascular Research, vol. 112, no. 2, pp. 568-580, 2016.

[138] P. Wenzel, M. Knorr, S. Kossmann et al., "Lysozyme Mpositive monocytes mediate angiotensin II-induced arterial hypertension and vascular dysfunction," Circulation, vol. 124, no. 12, pp. 1370-1381, 2011.

[139] M. A. Saleh, W. G. McMaster, J. Wu et al., "Lymphocyte adaptor protein LNK deficiency exacerbates hypertension and end-organ inflammation," The Journal of Clinical Investigation, vol. 125, no. 3, pp. 1189-1202, 2015. 
[140] C. T. Chan, J. P. Moore, K. Budzyn et al., "Reversal of vascular macrophage accumulation and hypertension by a CCR2 antagonist in deoxycorticosterone/salt-treated mice," Hypertension (Dallas, Tex. : 1979), vol. 60, no. 5, pp. 1207-1212, 2012.

[141] L. A. Cassis, S. B. Police, F. Yiannikouris, and S. E. Thatcher, "Local adipose tissue renin-angiotensin system," Current Hypertension Reports, vol. 10, no. 2, pp. 93-98, 2008.

[142] B. Gálvez-Prieto, J. Bolbrinker, P. Stucchi et al., "Comparative expression analysis of the renin-angiotensin system components between white and brown perivascular adipose tissue," The Journal of Endocrinology, vol. 197, no. 1, pp. 55-64, 2008.

[143] A. Nguyen Dinh Cat and R. M. Touyz, "A new look at the renin-angiotensin system-focusing on the vascular system," Peptides, vol. 32, no. 10, pp. 2141-2150, 2011.

[144] L. te Riet, J. H. M. van Esch, A. J. M. Roks, A. H. van den Meiracker, and A. H. J. Danser, "Hypertension," Circulation Research, vol. 116, no. 6, pp. 960-975, 2015.

[145] L. Chang, W. Xiong, X. Zhao et al., "Bmal 1 in perivascular adipose tissue regulates resting-phase blood pressure through transcriptional regulation of angiotensinogen," Circulation, vol. 138, no. 1, pp. 67-79, 2018.

[146] T. P. Mikolajczyk, R. Nosalski, D. S. Skiba et al., “1,2,3,4,6Penta-O-galloyl- $\beta$-d-glucose modulates perivascular inflammation and prevents vascular dysfunction in angiotensin IIinduced hypertension," British Journal of Pharmacology, vol. 176, no. 12, pp. 1951-1965, 2019.

[147] S. Kagota, K. Maruyama-Fumoto, M. Shimari, J. J. McGuire, and K. Shinozuka, "Angiotensin II type 1 receptor antagonist azilsartan restores vascular reactivity through a perivascular adipose tissue-independent mechanism in rats with metabolic syndrome," Cardiovascular Drugs and Therapy, vol. 33, no. 5, pp. 501-509, 2019.

[148] T. Wei, J. Gao, C. Huang, B. Song, M. Sun, and W. Shen, "SIRT3 (Sirtuin-3) Prevents Ang II (Angiotensin II)-Induced Macrophage Metabolic Switch Improving Perivascular Adipose Tissue Function," Arteriosclerosis, Thrombosis, and Vascular Biology, vol. 41, no. 2, pp. 714-730, 2021.

[149] P. Liu, Q. Xie, T. Wei, Y. Chen, H. Chen, and W. Shen, “Activation of the NLRP3 inflammasome induces vascular dysfunction in obese OLETF rats," Biochemical and Biophysical Research Communications, vol. 468, no. 1-2, pp. 319-325, 2015.

[150] X. Unamuno, J. Gómez-Ambrosi, B. Ramírez et al., "NLRP3 inflammasome blockade reduces adipose tissue inflammation and extracellular matrix remodeling," Cellular \& Molecular Immunology, vol. 18, no. 4, pp. 1045-1057, 2019.

[151] N. S. Ferreira, R. C. Tostes, P. Paradis, and E. L. Schiffrin, "Aldosterone, inflammation, immune system, and hypertension," American Journal of Hypertension, vol. 34, no. 1, pp. 15-27, 2021.

[152] F. Mayyas, K. H. Alzoubi, and D. R. van Wagoner, "Impact of aldosterone antagonists on the substrate for atrial fibrillation: aldosterone promotes oxidative stress and atrial structural/ electrical remodeling," International Journal of Cardiology, vol. 168, no. 6, pp. 5135-5142, 2013.

[153] I. Sudano, F. Ruschitzka, G. Noll, and T. F. Luscher, "Endothelial function and the effects of aldosterone blockade," European Heart Journal Supplements, vol. 13, Supplement_ B, pp. B21-B26, 2011.

[154] A. M. Briones, A. Nguyen Dinh Cat, G. E. Callera et al., "Adipocytes produce aldosterone through calcineurin-dependent signaling pathways," Hypertension, vol. 59, no. 5, pp. 10691078, 2012.

[155] Y.-C. Lee, H. H. Chang, C. L. Chiang et al., "Role of perivascular adipose tissue-derived methyl palmitate in vascular tone regulation and pathogenesis of hypertension," Circulation, vol. 124, no. 10, pp. 1160-1171, 2011.

[156] T. J. Guzik, R. Olszanecki, J. Sadowski et al., "Superoxide dismutase activity and expression in human venous and arterial bypass graft vessels," Journal of Physiology and Pharmacology, vol. 56, no. 2, pp. 313-323, 2005.

[157] T. Szasz, G. F. Bomfim, and R. C. Webb, "The influence of perivascular adipose tissue on vascular homeostasis," Vascular Health and Risk Management, vol. 9, pp. 105-116, 2013.

[158] C. M. Sena, A. Leandro, L. Azul, R. Seiça, and G. Perry, "Vascular oxidative stress: impact and therapeutic approaches," Frontiers in Physiology, vol. 9, p. 1668, 2018.

[159] S. E. L. Even, M. G. Dulak-Lis, R. M. Touyz, and A. Nguyen Dinh Cat, "Crosstalk between adipose tissue and blood vessels in cardiometabolic syndrome: implication of steroid hormone receptors (MR/GR)," Hormone Molecular Biology and Clinical Investigation, vol. 19, no. 2, pp. 89101, 2014.

[160] R. Nosalski, T. Mikolajczyk, M. Siedlinski et al., "Nox1/4 inhibition exacerbates age dependent perivascular inflammation and fibrosis in a model of spontaneous hypertension," Pharmacological Research, vol. 161, article 105235, 2020.

[161] J. Wu, M. A. Saleh, A. Kirabo et al., "Immune activation caused by vascular oxidation promotes fibrosis and hypertension," The Journal of Clinical Investigation, vol. 126, no. 1, pp. 50-67, 2016.

[162] U. Landmesser, H. Cai, S. Dikalov et al., "Role of p47phoxin vascular oxidative stress and hypertension caused by angiotensin II," Hypertension (Dallas, Tex. : 1979), vol. 40, no. 4, pp. 511-515, 2002.

[163] K. Matsuno, H. Yamada, K. Iwata et al., "Nox1 is involved in angiotensin II-mediated hypertension: a study in Nox1deficient mice," Circulation, vol. 112, no. 17, pp. 2677-2685, 2005.

[164] S.-Z. Jiang, W. Lu, X. F. Zong, H. Y. Ruan, and Y. Liu, “Obesity and hypertension," Experimental and Therapeutic Medicine, vol. 12, no. 4, pp. 2395-2399, 2016.

[165] M. I. Yilmaz, A. Sonmez, K. Caglar et al., "Effect of antihypertensive agents on plasma adiponectin levels in hypertensive patients with metabolic syndrome," Nephrology (Carlton, Vic.), vol. 12, no. 2, pp. 147-153, 2007.

[166] A. S. Greenstein, K. Khavandi, S. B. Withers et al., "Local inflammation and hypoxia abolish the protective anticontractile properties of perivascular fat in obese patients," Circulation, vol. 119, no. 12, pp. 1661-1670, 2009.

[167] N. Xia, S. Horke, A. Habermeier et al., "Uncoupling of endothelial nitric oxide synthase in perivascular adipose tissue of diet-induced obese mice," Arteriosclerosis, Thrombosis, and Vascular Biology, vol. 36, no. 1, pp. 78-85, 2016.

[168] R. Aghamohammadzadeh, A. S. Greenstein, R. Yadav et al., "Effects of bariatric surgery on human small artery function: evidence for reduction in perivascular adipocyte inflammation, and the restoration of normal anticontractile activity despite persistent obesity," Journal of the American College of Cardiology, vol. 62, no. 2, pp. 128-135, 2013.

[169] H. Chen, M. Montagnani, T. Funahashi, I. Shimomura, and M. J. Quon, “Adiponectin Stimulates Production of Nitric 
Oxide in Vascular Endothelial Cells," The Journal of Biological Chemistry, vol. 278, no. 45, pp. 45021-45026, 2003.

[170] H. Vaverkova, D. Karasek, D. Novotny et al., "Positive association of adiponectin with soluble vascular cell adhesion molecule sVCAM-1 levels in patients with vascular disease or dyslipidemia," Atherosclerosis, vol. 197, no. 2, pp. 725-731, 2008.

[171] S. Nakanishi, K. Yamane, N. Kamei, H. Nojima, M. Okubo, and N. Kohno, "A protective effect of adiponectin against oxidative stress in Japanese Americans: the association between adiponectin or leptin and urinary isoprostane," Metabolism, vol. 54, no. 2, pp. 194-199, 2005.

[172] P. A. Kern, G. B. di Gregorio, T. Lu, N. Rassouli, and G. Ranganathan, "Adiponectin expression from human adipose tissue,” Diabetes, vol. 52, no. 7, pp. 1779-1785, 2003.

[173] M. Adamczak, A. Wiecek, T. Funahashi, J. Chudek, F. Kokot, and Y. Matsuzawa, "Decreased plasma adiponectin concentration in patients with essential hypertension," American Journal of Hypertension, vol. 16, no. 1, pp. 72-75, 2003.

[174] S. Maruyama, R. Shibata, R. Kikuchi et al., "Fat-derived Factor Omentin Stimulates Endothelial Cell Function and Ischemia- induced Revascularization via Endothelial Nitric Oxide Synthase-dependent Mechanism," The Journal of Biological Chemistry, vol. 287, no. 1, pp. 408-417, 2012.

[175] C. M. de Souza Batista, R. Z. Yang, M. J. Lee et al., "Omentin plasma levels and gene expression are decreased in obesity," Diabetes, vol. 56, no. 6, pp. 1655-1661, 2007.

[176] Y. Du, Q. Ji, L. Cai et al., "Association between omentin-1 expression in human epicardial adipose tissue and coronary atherosclerosis," Cardiovascular Diabetology, vol. 15, no. 1, p. 90, 2016.

[177] A. Planavila, I. Redondo-Angulo, F. Ribas et al., "Fibroblast growth factor 21 protects the heart from oxidative stress," Cardiovascular Research, vol. 106, no. 1, pp. 19-31, 2015.

[178] Y. Zhang, Z. Liu, M. Zhou, and C. Liu, “Therapeutic effects of fibroblast growth factor-21 against atherosclerosis via the NF- $\kappa$ B pathway," Molecular Medicine Reports, vol. 17, no. 1, pp. 1453-1460, 2018.

[179] X. Pan, Y. Shao, F. Wu et al., "FGF21 Prevents Angiotensin II-Induced Hypertension and Vascular Dysfunction by Activation of ACE2/Angiotensin-(1-7) Axis in Mice," Cell Metabolism, vol. 27, no. 6, pp. 1323-1337.e5, 2018.

[180] J. Rueda-Gotor, R. López-Mejías, S. Remuzgo-Martínez et al., "Vaspin in atherosclerotic disease and cardiovascular risk in axial spondyloarthritis: a genetic and serological study," Arthritis Research \& Therapy, vol. 23, no. 1, p. 111, 2021.

[181] K. Kauser, V. da Cunha, R. Fitch, C. Mallari, and G. M. Rubanyi, "Role of endogenous nitric oxide in progression of atherosclerosis in apolipoprotein E-deficient mice," American Journal of Physiology-Heart and Circulatory Physiology, vol. 278, no. 5, pp. H1679-H1685, 2000.

[182] T. Quaschning, F. Voss, K. Relle et al., "Lack of endothelial nitric oxide synthase promotes endothelin-induced hypertension: lessons from endothelin-1 transgenic/endothelial nitric oxide synthase knockout mice," Journal of the American Society of Nephrology, vol. 18, no. 3, pp. 730-740, 2007.

[183] L. T. Fourman, C. F. Saylor, L. Cheru et al., "Anti-Inflammatory interleukin 10 inversely relates to coronary atherosclerosis in persons with human immunodeficiency virus," The Journal of Infectious Diseases, vol. 221, no. 4, pp. 510-515, 2019.
[184] J. Mauer, B. Chaurasia, J. Goldau et al., "Signaling by IL-6 promotes alternative activation of macrophages to limit endotoxemia and obesity-associated resistance to insulin," Nature Immunology, vol. 15, no. 5, pp. 423-430, 2014.

[185] R. M. da Costa, R. S. Fais, C. R. P. Dechandt et al., "Increased mitochondrial ROS generation mediates the loss of the anticontractile effects of perivascular adipose tissue in high-fat diet obese mice," British Journal of Pharmacology, vol. 174, no. 20, pp. 3527-3541, 2017.

[186] H. Kirii, T. Niwa, Y. Yamada et al., "Lack of Interleukin-1 $\beta$ decreases the severity of atherosclerosis in ApoE-Deficient mice," Arteriosclerosis, Thrombosis, and Vascular Biology, vol. 23, no. 4, pp. 656-660, 2003.

[187] B. Schieffer, T. Selle, A. Hilfiker et al., "Impact of interleukin6 on plaque development and morphology in experimental atherosclerosis," Circulation, vol. 110, no. 22, pp. 34933500, 2004.

[188] E. S. Darios, B. M. Winner, T. Charvat, A. Krasinksi, S. Punna, and S. W. Watts, "The adipokine chemerin amplifies electrical field-stimulated contraction in the isolated rat superior mesenteric artery," American Journal of Physiology-Heart and Circulatory Physiology, vol. 311, no. 2, pp. H498-H507, 2016.

[189] G. K. Dimitriadis, J. Kaur, R. Adya et al., "Chemerin induces endothelial cell inflammation: activation of nuclear factorkappa beta and monocyte-endothelial adhesion," Oncotarget, vol. 9, no. 24, pp. 16678-16690, 2018.

[190] M. C. Ernst, M. Issa, K. B. Goralski, and C. J. Sinal, "Chemerin exacerbates glucose intolerance in mouse models of obesity and diabetes," Endocrinology, vol. 151, no. 5, pp. 1998-2007, 2010.

[191] S. I. Yamagishi, D. Edelstein, X. L. Du, Y. Kaneda, M. Guzmán, and M. Brownlee, "Leptin Induces Mitochondrial Superoxide Production and Monocyte Chemoattractant Protein-1 Expression in Aortic Endothelial Cells by Increasing Fatty Acid Oxidation via Protein Kinase A," The Journal of Biological Chemistry, vol. 276, no. 27, pp. 25096-25100, 2001.

[192] B. Gálvez-Prieto, B. Somoza, M. Gil-Ortega et al., “Anticontractile effect of perivascular adipose tissue and leptin are reduced in hypertension," Frontiers in Pharmacology, vol. 3, p. 103, 2012.

[193] M. R. Schroeter, N. Eschholz, S. Herzberg et al., "Leptindependent and leptin-independent paracrine effects of perivascular adipose tissue on neointima formation," Arteriosclerosis, Thrombosis, and Vascular Biology, vol. 33, no. 5, pp. 980-987, 2013.

[194] M. P. Reilly, M. Lehrke, M. L. Wolfe, A. Rohatgi, M. A. Lazar, and D. J. Rader, "Resistin is an inflammatory marker of atherosclerosis in humans," Circulation, vol. 111, no. 7, pp. 932-939, 2005.

[195] Y.-B. Lv, J. Jing, J. M. Li, J. P. Zhong, L. Fang, and B. Yang, "Assessment of RANTES levels as the indicators of plaque vulnerability in rabbit models of atherosclerosis," Pathology, Research and Practice, vol. 210, no. 12, pp. 1031-1037, 2014.

[196] P. Dorfmüller, V. Zarka, I. Durand-Gasselin et al., "Chemokine RANTES in severe pulmonary arterial hypertension," American Journal of Respiratory and Critical Care Medicine, vol. 165, no. 4, pp. 534-539, 2002.

[197] R. J. Aiello, P. A. K. Bourassa, S. Lindsey et al., "Monocyte chemoattractant protein-1 accelerates atherosclerosis in 
apolipoprotein E-deficient mice," Arteriosclerosis, Thrombosis, and Vascular Biology, vol. 19, no. 6, pp. 1518-1525, 1999.

[198] J. Podolec, G. Kopec, L. Niewiara et al., "Chemokine RANTES is increased at early stages of coronary artery disease," Journal of Physiology and Pharmacology, vol. 67, no. 2, pp. 321-328, 2016 .

[199] J. Chamberlain, S. Francis, Z. Brookes et al., "Interleukin-1 regulates multiple atherogenic mechanisms in response to fat feeding," PLoS One, vol. 4, no. 4, article e5073, 2009.

[200] R. Li, A. Paul, K. W. S. Ko et al., "Interleukin-7 induces recruitment of monocytes/macrophages to endothelium," European Heart Journal, vol. 33, no. 24, pp. 3114-3123, 2012.

[201] L. Ziegler, J. Lundqvist, K. Dreij et al., "Expression of Interleukin 6 signaling receptors in carotid atherosclerosis," Vascular Medicine, vol. 26, no. 1, pp. 3-10, 2020.

[202] Y. Zhang, X. Yang, F. Bian et al., "TNF- $\alpha$ promotes early atherosclerosis by increasing transcytosis of LDL across endothelial cells: crosstalk between NF- $\kappa \mathrm{B}$ and PPAR- $\gamma$," Journal of Molecular and Cellular Cardiology, vol. 72, pp. 85-94, 2014.

[203] U. C. Broedl, C. Lebherz, M. Lehrke et al., "Low adiponectin levels are an independent predictor of mixed and noncalcified coronary atherosclerotic plaques," PLoS One, vol. 4, no. 3, article e4733, 2009.

[204] Z. Wang, C. Li, X. Sun et al., "Hypermethylation of miR-181b in monocytes is associated with coronary artery disease and promotes M1 polarized phenotype via PIAS1-KLF4 axis," Cardiovascular Diagnosis and Therapy, vol. 10, no. 4, pp. 738-751, 2020.

[205] M.-H. Zhang, Y. X. Cao, L. G. Wu et al., "Association of plasma free fatty acids levels with the presence and severity of coronary and carotid atherosclerotic plaque in patients with type 2 diabetes mellitus," BMC Endocrine Disorders, vol. 20 , no. 1, p. 156, 2020.

[206] T. A. Jacinto, G. S. Meireles, A. T. Dias et al., "Increased ROS production and DNA damage in monocytes are biomarkers of aging and atherosclerosis," Biological Research, vol. 51, no. 1, p. 33, 2018.

[207] A. G. Herman and S. Moncada, "Therapeutic potential of nitric oxide donors in the prevention and treatment of atherosclerosis," European Heart Journal, vol. 26, no. 19, pp. 1945-1955, 2005.

[208] Y. Lin, H. Zeng, L. Gao, T. Gu, C. Wang, and H. Zhang, "Hydrogen Sulfide attenuates atherosclerosis in a partially ligated carotid artery mouse model via regulating angiotensin converting enzyme 2 expression," Frontiers in Physiology, vol. 8, p. 782, 2017.

[209] C. Buono, C. E. Come, G. Stavrakis, G. F. Maguire, P. W. Connelly, and A. H. Lichtman, "Influence of Interferon- $\gamma$ on the Extent and Phenotype of Diet-Induced Atherosclerosis in the LDLR-Deficient Mouse," Arteriosclerosis, Thrombosis, and Vascular Biology, vol. 23, no. 3, pp. 454-460, 2003.

[210] P. F. Bodary, S. Gu, Y. Shen, A. H. Hasty, J. M. Buckler, and D. T. Eitzman, "Recombinant leptin promotes atherosclerosis and thrombosis in apolipoprotein E-deficient mice," Arteriosclerosis, Thrombosis, and Vascular Biology, vol. 25, no. 8, pp. e119-e122, 2005.

[211] T. B. Dahl, A. Yndestad, M. Skjelland et al., "Increased expression of visfatin in macrophages of human unstable carotid and coronary atherosclerosis," Circulation, vol. 115, no. 8, pp. 972-980, 2007.
[212] S. C. A. de Jager, A. O. Kraaijeveld, R. W. Grauss et al., "CCL3 $(\mathrm{MIP}-1 \alpha)$ levels are elevated during acute coronary syndromes and show strong prognostic power for future ischemic events," Journal of Molecular and Cellular Cardiology, vol. 45, no. 3, pp. 446-452, 2008.

[213] D. Tsiantoulas, I. Bot, M. Ozsvar-Kozma et al., "Increased plasma IgE accelerate atherosclerosis in secreted IgM deficiency," Circulation Research, vol. 120, no. 1, pp. 78-84, 2017.

[214] L. E. Bautista, L. M. Vera, I. A. Arenas, and G. Gamarra, "Independent association between inflammatory markers (C-reactive protein, interleukin-6, and TNF- $\alpha$ ) and essential hypertension," Journal of Human Hypertension, vol. 19, no. 2, pp. 149-154, 2005.

[215] M. Buemi, D. Marino, F. Floccari et al., "Effect of interleukin 8 and ICAM- 1 on calcium-dependent outflow of $\mathrm{K}+$ in erythrocytes from subjects with essential hypertension," Current Medical Research and Opinion, vol. 20, no. 1, pp. 19-24, 2004.

[216] A. Cortez and E. Muxfeldt, "Proteina 1 quimioatrayente de monocitos e hipertension: generalidades," Hipertensión y Riesgo Vascular, vol. 38, no. 4, 2021.

[217] P. Chatterjee, V. L. Chiasson, G. Seerangan et al., "Cotreatment with interleukin 4 and interleukin 10 modulates immune cells and prevents hypertension in pregnant mice," American Journal of Hypertension, vol. 28, no. 1, pp. 135$142,2015$.

[218] S. D. Crowley, S. B. Gurley, M. J. Herrera et al., “Angiotensin II causes hypertension and cardiac hypertrophy through its receptors in the kidney," Proceedings of the National Academy of Sciences of the United States of America, vol. 103, no. 47, pp. 17985-17990, 2006.

[219] M. A. Sparks, J. Stegbauer, D. Chen et al., "Vascular type 1A angiotensin II receptors control BP by regulating renal blood flow and urinary sodium excretion," Journal of the American Society of Nephrology, vol. 26, no. 12, pp. 2953-2962, 2015.

[220] S. Cottone, G. Mule, M. Guarneri et al., "Endothelin-1 and F2-isoprostane relate to and predict renal dysfunction in hypertensive patients," Nephrology, Dialysis, Transplantation, vol. 24, no. 2, pp. 497-503, 2009.

[221] A. Troia, R. H. Knutsen, C. M. Halabi et al., "Inhibition of NOX1 Mitigates Blood Pressure Increases in Elastin Insufficiency," Function, vol. 2, no. 3, article zqab015, 2021.

[222] G. Engström, B. Hedblad, G. Berglund, L. Janzon, and F. Lindgärde, "Plasma levels of complement C3 is associated with development of hypertension: a longitudinal cohort study," Journal of Human Hypertension, vol. 21, no. 4, pp. 276-282, 2007. 